\title{
Problemas en el Sur: Puno en los procesos de transformación del Capitalismo Global ${ }^{1}$
}

\section{Problems in the South: Puno in the processes of transformation of Global Capitalism}

\author{
Franklin Américo Canaza-Choque ${ }^{2}$ \\ Universidad Nacional de San Agustín de Arequipa \\ fcanazach@unsa.edu.pe \\ https://orcid.org/0000-0002-1929-6054
}

Recibido: 12/05/2019 - Aceptado: 9/06/2020 - Publicado: 06/12/2021

\section{RESUMEN}

Pasado 1990, el capitalismo ha desarrollado intempestivamente una serie de engranajes en su propio y adecuado funcionamiento como sistema-mundo, de renovarse cuantas veces quiera ante una crisis que especule su final apocalíptico. Es el capital, primero un factor decisivo en la producción, y a la vez, un poder que no obedece ley alguna sobre cómo se han fijado las cosas y el orden en el mundo. Es así, que las circunstancias del momento han sido aprovechados de algún modo por redes y nudos económicos capitalizadores de bienes comunes. Es sobre esta moldura expansiva de razones prácticas que la economía puneña se desenvuelve día a día, quizás de la mejor manera, en donde las relaciones sociales, los modos de producción y de flujos económicos locales están suficientemente encadenados a tasas de crecimiento económico fijados y concentrados en el sector primario, particularmente, agropecuario y minero, aquí, es donde las grandes dosis del mercado mundial presionan fuertemente. En este afán, el estudio analiza una de las regiones del país condenado a la minería: Puno. Región lacustre, que en el transcurrir de los años se ha convertido en

(C) Los autores. Este artículo es publicado por Pensamiento Crítico de la Facultad de Ciencias Económicas, Universidad Nacional Mayor de San Marcos. Este es un artículo de acceso abierto, distribuido bajo los términos de la licencia Creative Commons Atribucion - No Comercia_Compartir Igual 4.0 Internacional. (http://creativecommons.org/licenses/by-nc-sa/4.0/) que permite el uso no comercial, distribución y reproducción en cualquier medio, siempre que la obra original sea debidamente citada. 
el foco de una enorme cadena capitalizadora de recursos naturales y de expropiación territorial infinitamente insostenible.

Palabras clave: Capitalismo; conflictos sociales; inversión minera; recursos naturales. JEL: D74, E22, F54, L12, P1.

\section{ABSTRACT}

Past 1990, capitalism has developed a series of gears on its own and proper functioning as world-system, to renew as many times as you want in the face of a crisis that speculates its apocalyptic end. It is capital, first a decisive factor in production, and at the same time a power that does not obey any law on how things have been set and order in the world, it is like that, that the circumstances of the moment have been taken advantage of in some way by networks and economic knots capitalizers common goods. It is on this expansive molding of practical reasons that the economy puneña unfolds day by day, perhaps in the best way, where social relations, modes of production and local economic flows are sufficiently chained to fixed and concentrated economic growth rates in the primary sector, particularly, agricultural and mining, here, is where the big doses of world market strongly press. In this effort, the study analysis one of regions the country condemned to mining: Puno. Lake region, which over the years has become the focus of a huge capitalize chain of natural resources and territorial expropriation infinitely unsustainable.

Keywords: Capitalism; social conflicts; mining investment; natural resources.

JEL: D74, E22, F54, L12, P1. 


\section{Introducción}

Dentro del repertorio de desplazamiento y desborde social, uno de los conflictos de carácter socioambiental de arraigue histórico y más agudo presentado en la región Sur del país, fue el caso de Santa Ana en 2011 (Puno), proyecto minero de la empresa canadiense Bear Creek Mining Company, Sucursal Perú (BCMC-SP), que debido a sus propias fallas e irregularidades en cuanto a las formas de operancia y extracción de plata (Pinto, 2013), su alcance y mediación con las comunidades, anexados a un temor extendido de contaminación a plataformas medioambientales que se apoderaron por completo de las subjetividades de aquellos pobladores asentados en Huacullani y Kelluyo, provincia de Chucuito-Juli (CanazaChoque, 2018b), terminaron siendo para este episodio, un punto explosivo de no retorno de dos fuerzas dirigidas en dirección inversa mientras duraba el gobierno del entonces presidente de la República del Perú, Alan García (2006-2011).

Pues, lo que parecía ser un pequeño y expreso rechazo al proyecto de exploración minera Santa Ana, acabó de por sí, mutando a este último en el entretejimiento de un movimiento social masivo denominado "Aymarazo" que, por sus derivaciones puso a debatir las complicaciones y limitantes de los modelos de desarrollo extractivo de la poderosa maquinaria capitalista. Llevándolo a este, al final de un cierre definitivo de la concesión minera que fue afinando, sin lugar a dudas, futuros estragos y puntos de inflexión social del tensado régimen económico instalado en las regiones del Sur.

No obstante, esta furia desatada y de lucha antiminera sería un referente con matices discursivos y componentes políticos de momento (Merlinsky, 2017) que serviría siete años después, de canon y soporte en la partida electoral del Movimiento de Integración por el Desarrollo Regional (Mi Casita) liderado por el expresidente del Frente de Defensa de Recursos Naturales de la Zona Sur y político aymara Walter Aduviri Calisaya, quien a pesar de ser el coautor mediato no ejecutivo del delito contra la tranquilidad pública (Perú21, 2018) en razón de buscar la cancelación de las actividades extractivas del proyecto minero Santa Ana, acabaría por convertirse en primera vuelta de las Elecciones Regionales y Municipales (ERM) de octubre de 2018 en el Gobernador Regional de Puno para 
el período 2019-2022. Un corto lapso de transición y delimitado por los mismos efectos sobrevenidos del estallido social de 2011.

Pues, mucho antes de que se dictaminara el fallo de la Corte Suprema de Justicia de Puno y del posterior detenimiento del personaje en clandestinidad y de fuerte expectativa de cambio y reforma para la población más desprovista, Walter Aduviri asumiría el gobierno la primera semana de enero de 2019 en medio de un tenso recorrido y de un nuevo proceso judicial que sellaría su destino el pasado 26 de agosto de 2019 con seis años de pena privativa de la libertad por el denominado y llamativo paro antiminero desatado el 26 de mayo de 2011.

Fechas previas a este final, la asunción del poder del destronado y antes dirigente tuvo una doble ceremonia de inicio, donde el líder aymara dejaría en claro en cuanto a su posición del modelo económico regional. Primero, este declararía no estar en contra de la minería, sino más bien, la idea básica era buscar que esta constituya y beneficie en gran medida a la población quechua-aimara. Por ello, apostaría desde ya, en apoyar la minería en pequeña escala asumiendo tipologías de producción y reproducción al estilo del Estado Plurinacional de Bolivia (Observatorio de Conflictos Mineros en el Perú OCM], 2018b).

Pese a esto, lo que Aduviri no tomaba en cuenta de la experiencia del país sureño, es que el gobierno progresista de Evo Morales Ayma (20062019), en el afán máximo de aumentar las capacidades de crecimiento endógeno productivo y modernizarlas bajo una triangulación de tecnología-industria y política, con la idea autonómica de ganar espacios frente a la economía global, lo condujeron a primar una sobreexplotación de los recursos naturales y la reprimarización de la economía. Tornándose así, un perfil neoextractivo como lógica de funcionamiento en los extensos territorios ricos en minerales del Estado boliviano (Fornillo, 2018).

En paralelo, de acuerdo a los diferentes estudios desplegados en la zona Sur del Perú (Ccopa, 2014; Ministerio de Energía y Minas [MINEM], 2017; Solís, 2018; Mayer y Vásquez, 2018). No extraña que Puno sea una de las regiones con la mayor concentración de recursos mineros polimetálicos, siendo los más importantes: el estaño, plomo, oro, plata, zinc, tungsteno, magnesio, uranio, y recientemente, las prometedoras reservas de "oro blanco" (litio) hallado en los depósitos de Falchani (Macusani-Puno); y, 
que según las estimaciones de la empresa minera multinacional Macusani Yellowcake subsidiaria de la canadiense Plateau Energy Metals, podría ser este, uno de los yacimientos de reserva de litio más grande del planeta que tasarían una producción valorizada de 60,000 toneladas métricas de carbonato de litio por año. Así, con una inversión de 1,100 millones de US\$ y el aprovechamiento de 2,5 millones de toneladas del metal radioactivo se tendría una vida garantizada de 40 años de explotación en dicha zona descubierta (Solís, 2018).

De lo anterior, en el trasfondo, el litio, según el Banco Mundial (BM) comprende uno de los 12 metales del futuro por su amplia aplicación industrial y de impetración en el mercado global, fundamento básico que asoman al Perú entre las grandes ligas de la minería de litio que implicaría 100 años de explotación rentable. Y que a manera de referencia, según la Agencia Alemana de Recursos Minerales (DERA), la demanda mundial de litio se duplicaría en el 2025. Haciendo de este metal, uno de los más atractivos y deseosos para la inversión de la gran industria en Perú y del extranjero (Mayer y Vásquez, 2018).

De igual manera, tales condiciones han llevado a aseverar que el 60\% del territorio altiplánico es, en definitiva, potencial vasto para la explotación de recursos minerales. Dada las circunstancias, los reportes del Instituto Geológico, Minero y Metalúrgico (INGEMMET) consideran que actualmente la región posee cerca de 4 mil 473 concesiones mineras sobre un espacio geográfico de más de 2 millones 520 mil 025 hectáreas, de los cuales, el $80 \%$ son de espacios metálicos y el resto, no metálicos (20\%). Asimismo, las provincias mayoritariamente concesionadas son: San Román, Azángaro, Lampa, Melgar, Carabaya, Putina, Sandia y Puno (Ccopa, 2014).

Provincias en donde colosales compañías asientan su actividad productora en la extracción de recursos naturales de origen mineral, cuyas formas de explotación infinita consiguen afectar de manera negativa al sector agropecuario; a fuentes hídricas; la modificación de paisajes; la alteración de patrimonios culturales e identitarios de incontables comuneros a quienes se les ha cuestionado su existir en modo y forma. Un proceso de acumulación de riqueza y de transformación única de factores productivos que ha consumado todas las leyes de la naturaleza en la aspiración 
decisiva de maximizar las ganancias y de repotenciar los flujos fiscales sobre una tierra unida en gran parte a enormes inventarios minerales.

Por ende, la expansión irrefrenable de proyectos mega-mineros de explotación metálica, no es un fenómeno apartado del sistema-mundo, sino, un asunto inserto dentro de un tejido estructural de transformaciones del capitalismo estrechamente ligado a los poderes cimentados e insostenibles de la ya reconfigurada modernidad que tiene como blanco un período de acumulación por desposesión concentrando una riqueza antes imposible de imaginar (Harvey, 2005; 2012). Circunstancias que han empujado a los límites los derechos humanos y la suficiencia de la tierra, que al tiempo, requieren de reajustes (Peláez, 2015) en una época en el que las fronteras nacionales se hacen inservibles ante las ventajas fiscales de contenidos neoliberales que desmontan todas las estructuras estatales a un carácter de capital transnacional (Wagner y Pinto, 2013).

\section{Figura 1}

Walter Aduviri: La figura de quien emprendería una de las movilizaciones sociales más grandes en el Sur del país.

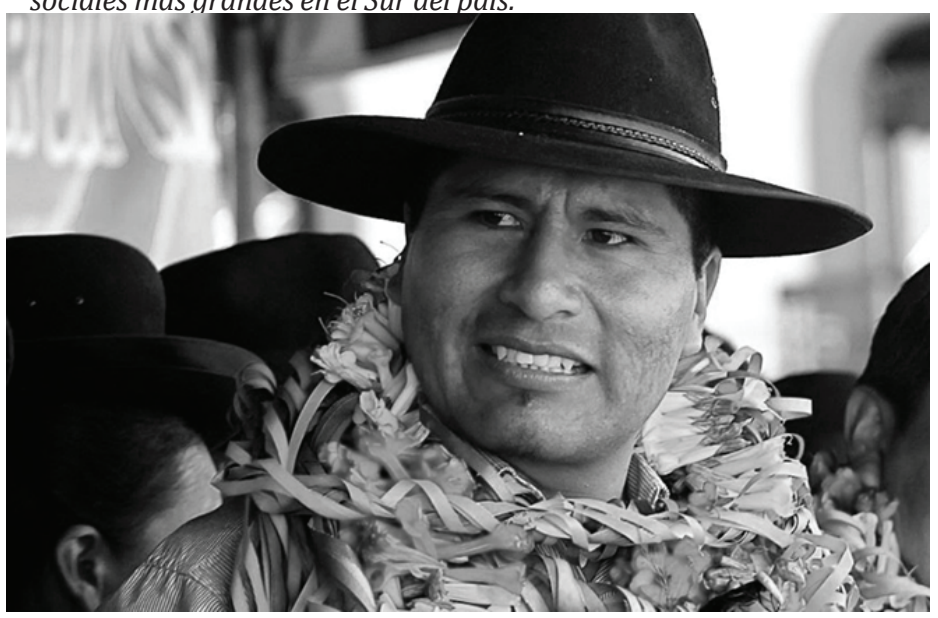

Fuente: Andina (2018b).

En ese afán, el estudio analiza la dinámica productora de una de las regiones del país condenado a la minería: Puno (Perú). Región lacustre, que en el transcurrir de los años se ha convertido en el foco de una enorme cadena capitalizadora de recursos naturales y de expropiación territorial 
que, por esta misma razón, el modelo depredador ha significado ser una amenaza para salud, el medio ambiente, los derechos humanos, la cultura e integridad de las personas ajustadas a su dominio y radio de proyección, en cuyos ritmos desenfrenados, cuesta asumir la vida frente a la muerte.

Es así que, para comprender este episodio tenso para muchos de los agentes captados por este poder intermitente. Definir y reconocer el movimiento que hace posible de que enormes volúmenes de recursos naturales sean explotados sin medida, es entre ver en el modelo extractivo acentos imparables en donde las tasas de extracción son mayores a las tasas ecológicas, una práctica indispensable para las economías globales del Norte, que parecen estar en la médula de una propuesta mundo basada en la acumulación y bonanza de recursos (Acosta, 2011).

\section{Marco Teórico}

\subsection{Capitalismo global y procesos de tensión}

Desde la década de 1990, las fuertes pretensiones de reestructurar las funciones internas del Estado y el proceso de imposición demostrativodeliberativo del modelo neoliberal tuvo, entre las diversas formas de efecto trazado de inicio a fin, la reducción o desaparición total del Estado benefactor (Brand, 2000). Esto último, fue decisivo para determinar frutos interminables y hacer notar en el Estado; primero, el problema insalvable dentro de su propia dinámica referida a que el mercado depende de la producción privada y del inmutable proceso de reinversión, en donde el aparato estatal no solo debe regular tales propósitos de desenvolvimiento, sino también, de resguardar y promover este mismo intercambio mercantil y de inversión privada que lo terminaría, inevitablemente, desmantelando mientras durara la tendencia (Medina, 1998).

De igual modo, la predictible reducción del tamaño del Estado y el ascenso resonante del neoliberalismo trajo consigo; por un lado, el desplazamiento de fuertes políticas de desregularización, privatización expansiva y la liberalización del comercio transfronterizo, así como la eliminación de aranceles sobre las importaciones y el movimiento de recursos en regiones poco previstas que, acabaron replanteando el preestablecido orden normativo-social, los mercados financieros y la manera moderna 
de capital-dinero (López, 2021). Por otro lado, debido a la configuración del terreno y las nuevas formas de formación de interdependencia, el período de predominancia de libre mercado tuvo como resultado indefectible el escalamiento y la ampliación de brechas sociales, económicas y tecnológicas entre potencias y países pobres tanto fuera como dentro de ellas (Robayo, 2021). Disolviendo de esta manera, pasadas y fijadas formas de estructura, organización y desempeño productivo global (Canaza-Choque, 2019).

En esa medida, tales transformaciones enlazadas a rasgos fundamentales de superurbanización planetaria, revolución tecnológica y de la instauración imponente de un proceso globalizador irreversible denotaron el desarrollo y el establecimiento de un capitalismo avanzado (Sassen, 2015). Así, la imposición implicaba reformar nuevas mega-estructuras de producción, técnicas de gestión, comercio y finanzas. Pero sin duda, la fuerza determinante para su profunda expansión de intensidad, extensión geográfica y de traspase de frontera regional, localizaron en las redes de integración de la economía internacional, la aplicación de políticas neoliberales de ultranza y el aprovechamiento de coordenadas macroeconómicas por parte de las empresas, las condiciones necesarias para el despegue del sistema hegemónico (Frieden, 2007).

De esta manera, en el transformado terreno, todas las demás relaciones sociales, los modos de producción y dimensiones de la realidad fueron indefectiblemente articuladas a los efectos de la mundialización exacerbada y direccionada por el capital financiero internacional (Frieden, 2007). Desde ese punto, la legitimidad valorada del sistema y su marcada continuidad durante las últimas décadas, de acuerdo con Wallerstein (1999), tiene su principio preeminente en los preformados bloques o las parciales alianzas establecidas entre productores locales que buscaron una expansión mercantil y por Estados que aspiraron a una expansión territorial, de control y de procesos de apropiación de recursos. Estableciendo de ese modo, una relación de poder de clase dominante que no tenga un contrapeso alguno o de contrafuerza definida que pueda derribarlo.

Igualmente, para Houtart (2009), el capitalismo como sistema, aterriza dentro de actividades regidas en función de la oferta y la demanda, con el propósito máximo de intensificar la primera y extender fuertemente la segunda. De esta forma, sobrepone al capital por encima de los demás factores 
de producción, y no sin razones. Pues, para los propietarios o dueños, este último, dispensa un valor adicional a la producción de bienes y servicios o a la repotencialización del desempeño laboral y los niveles de productividad. Esto, con el fin detonante de favorecer a la acumulación de un capital que permita y este destinado a la reinversión de nuevos proyectos económicos. Estando el mercado, en el medio de ese programa para imponerse en las diferentes formas de reorganización general. De tal manera que, la influencia y el poder del privilegiado y preponderante funcionamiento del capital resulta ser clave en todas las actividades económicas.

Desde otro lado, para Peinado (2011), el actual sistema económicosocial modela el entorno global mediante una fuerte tasación del capital en todas sus formas que, desbordando los límites nacionales, el poder Estatal, la fuerza del mercado y de las diferentes dinámicas del crecimiento económico, se ha implantado en un proceso único de acumulación de capital que redefine la reproducción del desarrollo en distintos países. Sumado a esto, según Harvey (2012), esta ampliación del capital más allá de delinear su dominio desemboca en desiguales emplazamientos de desarrollo geográfico. En donde el renovado y nombrado proceso de acumulación por desposesión planea la capitalización de la tierra, el influjo de los recursos naturales y públicos, la apoderación dilatada de fuentes proclives de explotación desmedida. Introduciendo, en cada una de ellas sin importar el espacio ni el tiempo, una modalidad de circuitos de producción encadena regidos por el capital en donde el propósito supremo, reside en extraer una renta o beneficio del patrimonio acumulado.

De esta manera, la reproducción del régimen tiene un itinerario y destino definido en privatizar, monetizar y comercializar intensa y a niveles profundos todo el registro finito e infinito o de aspectos que puedan ser transformados en una forma de capital (Harvey, 2014). Donde nada puede deslizarse o eludir a este desfiguramiento provocado por el desarrollo exponencial de estrategias de acumulación y de una forzada colonización del espacio y del establecimiento del dominio de un reducido grupo de personas sobre el resto de la población.

En ese sentido, dentro de su propia formación y de la in-localización del poder dirigente (Montañez, 2018). Este sistema-mundo basado en la acumulación interminable de capital propicia un incremento en los niveles de desigualdad y de quebrar las delgadas líneas que dividen a los estratos 
altos de los de abajo (Milanovic, 2019). Disparidad que termina perpetrándose y dando forma a otros problemas regentes de estanque en la medida en que la acumulación del capital y la riqueza sea desproporcionada y siga su movimiento en la economía mundial.

\subsection{Depredación territorial y desposesión en el Sur}

Frente al desafío de rastrear y renovar la descripción que hace Marx (18181883) de la acumulación originaria de un proceso en curso y tendente al expansionismo. Para Harvey (2005), reemplazar este planteamiento por un término mejor desarrollado al que designa como acumulación por desposesión. Implica, establecer un perfeccionado demarcador que puede propiamente explicar sin fallo alguno aspectos dominantes y tornadizos de la dinámica reforzada del actual capitalismo global. Dado que los efectos de este último, dentro de ese rango de expansión y movimiento, revela un amplio nivel de impactos que incluyen políticas de privatización en el terreno urbano; la expropiación del dominio y la expulsión de los moradores de la tierra; la conversión de la propiedad pública en títulos privados; la destrucción irreparable de los recursos y el espacio natural; la apropiación de activos y la transformación de la fuerza laboral en mercancía; la monetarización del intercambio y de la planeación de estructuras fiscales agresivas; la usura y el endeudamiento a través del crédito.

En medio de ese torrentoso resultado. El Estado neoliberal, dentro de su monopolización institucional, la violencia y la definición de legalidad, extiende (Guerra y Skewes, 2010). Por un lado, el desenvolvimiento de fuertes dinámicas de poder que facilitan la desposesión propietaria de diversas formas de producción por parte de un escalado de élites empresariales o megacorporaciones dispuestas a engrosar el régimen de despojo global (Sparke, 2008). Por otro lado, la promoción indefectible de estos mecanismos remueve desde el fondo los medios de producción, reorganiza las estructuras preexistentes y, por sobre todo, desarticula y debilita la placa social y la posibilidad de neutralizar el impacto del sistema.

Así, en ese escenario, el capital legitima los propósitos imperiosos del modelo rigiendo la dominación que se produce mediante la acumulación de riqueza y la incautación de bienes y recursos públicos. Entallando planes represores que superan los presupuestos de defensa estatal y comunal. Pues, 
una vez entrelazado las prácticas y el interés compartido de un Estado neoliberal con los grupos de poder y preparado el terreno para su funcionamiento, todo conduce a que exista un dominio capitalizador mucho más amplio en la geografía nacional, regional e internacional.

Imponiendo, en cada área apoderada, un alarmante aumento de desempleo, de efectos fatales en la democracia, la degradación de los derechos fundamentales, el empobrecimiento masivo de regiones explotadas por su gravedad y la destrucción medioambiental a una escala no programada (Sacher, 2015; Canaza-Choque y Huanca-Arohuanca, 2019). Donde los impactos demoledores de la depredación afectan principalmente a comunidades aledañas regidas por la pobreza y extrema pobreza o de la poca e inexistente presencia del Estado, siendo la minería, la industria manufacturera y nuclear, las principales culpables de esa devastación o aniquilación del territorio y la territorialidad (Sassen, 2015).

Desde esa línea, invariablemente la expansión ulterior y continua del capital puede dar forma a patrones peculiares en donde la formación de grandes cúmulos de capital físico y trabajo humano remodela el paisaje en uno irreconocible e inhabitable. Dado que, los procesos demandan implementar una mecánica predatoria de ingentes cantidades de fuente básica, el destierro de comunidades y de irremediables zonas dañadas con el fin preferente de extraer recursos y beneficios económicos a una velocidad que supera la capacidad de regeneración normal de los recursos.

Inclusive, una vez degastado las zonas de rentabilidad, la dilatada expansión procura aperturar regiones que antes se encontraban al margen del mercado (Sacher, 2015). Las razones de ello pueden tener una doble explicación. La primera, radica en establecer esencialmente dominadores y dominados desde el momento de su instalación, donde la reconstitución del poder territorial y el debilitamiento de la soberanía popular dan origen a nuevos modos de negociación de mando y obediencia. La segunda, desboca en que la persistente presión en la búsqueda de exprimir diametralmente el rendimiento de la zona titulada para la explotación termina afectando más allá del radio de transformación, lo que obliga en todo caso, una colonización del poder sobre la naturaleza y del control de extrañas y precarias áreas con tal de apagar las diminutas posibilidades de contragolpe o de rechazo al predominio de la industria extractiva. 
No obstante, para Sassen (2015), la extracción rampante de recursos, la acumulación equidistante del capital y las emergidas desigualdades sociales extremas dentro del territorio nacional, así como su progresivo ascenso. No implican ser eventos extraños. Dado que detrás de toda esta estructuración de anillo, se encuentran las políticas económicas desregulatorias y el extendido mecanismo de privatización liderado no solo por un Estado neoliberal, sino también, por fuerzas des-territoriales e indomables fuerzas tans-soberanas que, una vez ajustado la superficie de aprovechamiento, acaban imputando elevadas tasas de afectación a gobiernos nacionales y locales que, en el peor de los casos, concluye desarmando o enterrando la economía regional.

De este modo, estas denominadas formaciones predatorias no solamente requieren de una suma de avances tecnológicos, del aumento de redes financieras o de ostentar un mercado mucho más abierto al ingreso de caudales de inversión extranjera directa. Pues, este tipo de expulsión afrenta agnar complejos instrumentos de políticas públicas decantados a favor de los dueños del capital, de actores globales y de poderosos Estados que compartan una motivación en común (Sassen, 2015). La misma que se define en la apoderación de la riqueza a costa de la población; ya que, residir y habitar en una zona devastada, muy aparte de adicionar un alto riesgo para los habitantes, resta las mínimas condiciones de vivencia para los mismos.

Por debajo de esa línea, durante la primera década del 2000, la mayoría de los Estados neoliberales, progresistas y pos-neoliberales en Latinoamérica (Vallejo, Zamora y Sacher, 2019). Buscarían implementar importantes transformaciones políticas designadas a derrotar un numerario de imperfecciones que impedían el desarrollo, y así, reforzar los indicadores sociales de sectores urbanos y periurbanos (Biocca, 2020). No obstante, el derrotero a perseguir implicaba en cierta medida, profundizar actividades neoextractivas. Refinando desde el Estado la flexibilización normativa-fiscal, institucional y ambiental en materia de acceso a la tierra, además de remodelar la gobernabilidad y el ordenamiento territorial para facilitar la localización, extracción y transportación de los recursos a mercados expandidos (Vallejo et al., 2019). Todo este programa, únicamente era posible, relegando el interés y la demanda de poblaciones rurales, indígenas y de comunidades donde el impacto de la reestructurada producción dispondría múltiples afectaciones. 
De esta manera, en un marco particular de planificación territorial neoliberal que agenciaba intensificar procesos masivos de industrialización del capital en las regiones del Sur global (Homazabal, Maino, Vergara y Vergara, 2019). Las decisiones estatales apuntaron a privatizar empresas mineras de orden público, de proporcionar información geológica estratégica, así como de reorganizar la prestación de servicios en función de la inversión extranjera, de reducir la tasa tributaria y de templar el régimen arancelario e implementar mínimas medidas de protección medioambiental y de seguridad laboral. Desplegando, para efectos estrepitosos, una criminalización de la minería artesanal y de la protesta social (Sacher, 2015).

En ese recodo. No era raro de que el modelo en posición perfilara un extractivismo donde los agentes productores no tuvieran el interés de generar efectos multiplicadores de bienestar y seguridad social. Ni por supuesto, permitir a los antiguos residentes y pequeños productores locales que se beneficiasen de la dotación de recursos ni mucho menos de las explotaciones mineras (Merchand, 2013). Formando parte de su canon, una ininterrumpida expansión de fronteras y de zonas de sacrificio. Debido, principalmente, a la sobreexplotación y la escasa diversificación en el manejo de los recursos naturales (Vallejo et al., 2019).

No hay duda, de que este desdoblamiento moderno, posterior al funcionamiento de megaproyectos minero-energéticos radiaría, por un lado, destrucciones materiales e inmateriales de gran magnitud que, en una representatividad mayor han venido desproporcionadamente desterrando a las poblaciones de sus propios recursos y medios de subsistencia (Gordon y Webber, 2008). Sin embargo, de otro lado, esta dimensión destructora, de momento provocaría una resistencia de clase dominada que no solo buscaría hacer notar y reparar el daño lateral y el intermitente desempeño del modelo depredador, sino que además, el desatado e irrefrenable desplazamiento social de defensa pretendería desarmar o, por último, acabar con el sistema capitalista y de los diferentes dispositivos desenvueltos por este.

De igual modo, a pesar de esta reacción y del propósito de aniquilar el modelo por desposesión. El capitalismo emprende, antes que nada, reformas y reparaciones económicas destinadas a tomar en cuenta el plano medioambiental y las necesidades sociales o en un caso máximo, de 
indemnizar la falla provocada por su propia dinámica (Gudynas, 2013). Es aquí, en donde el reformado sistema prevalece intacto, y lo único que se realiza son renovaciones en el poder o de un reacomodo en su interior, sin trastocar nada en profundidad (Fernández, 2020). Así, en cada desbalance o de situación que implicase peligro, el capitalismo tiende a reestructurarse una y otra vez, resolviendo momentáneamente sus tensiones y contracciones. De manera que, esto último le permite renovar sus engranajes y sofisticar su arsenal en el próximo funcionamiento.

\section{Metodología}

\subsection{Definición y delimitación del espacio de estudio}

A 3810 msnm, en la bahía del lago más alto del mundo: El Titicaca, con una superficie de $8400 \mathrm{~km}^{2}$, resto de lo que fue antes el gran lago llamado Ballivián, yace la meseta del Collao y la cuenca compartida entre Perú (55\%) y Bolivia (45\%) (Ocola y Laqui, 2017). Ambas, rodeadas geográficamente por una red acuática (Ramis, Coata, Ilave, Huancané, Suches y Desaguadero) de gran aporte al ecosistema altiplánico y de las imponentes cordilleras de Carabaya, Vilcanota, Volcánica y del Barroso, que por los mismos efectos de un Calentamiento Global (CG) inevitable presumen una configuración morfológica en los macizos andinos, así como también, un cambio sustancial en el ambiente (relieve, flora y fauna), las condiciones de vida, la migración y de relaciones sociales de quienes están asentados en estas tierras de altura y demás cuerpos climáticos.

De lo antes descrito, no extraña que el rastreo informativo de 2013 hecho por la Autoridad Nacional del Agua (ANA), den cuenta de que el 57\% de glaciares se perdieron a causa del CG. Así, los pronósticos conducen a una amenazante desglaciación que pone en peligro la disponibilidad de agua y de fuentes hídricas en el país, y más aún, en la región sureste del Perú (CooperAcción, 2017).

Es aquí, y no en otro lugar, a una altura de $3827 \mathrm{msnm}$, entre $15^{\circ} 50^{\prime} 15^{\prime \prime}$ latitud sur y $70^{\circ} 01^{\prime} 18^{\prime \prime}$ longitud oeste del meridiano de Greenwich (Tudela-Mamani, 2017), con una estimación promedio al 2020 de 1,485,328 habitantes de regiones gélidas (Instituto Nacional de Estadística e Informática [INEI], 2009) es que se encuentra Puno. Región de suelos abatidos 
por la pobreza económica y de condiciones climáticas extremas y de una compleja trama cultural en donde las poderosas fuerzas demoledoras del capitalismo global han conseguido operar de indistinta manera y forma en regiones tan endebles, pero de enormes yacimientos mineros.

Por ello no extraña, que el capital foráneo haya concentrado su eje potenciador en la minería tradicional, particularmente, aquella asociada a la explotación de minerales como el oro, cobre, plomo y estaño, sin dejar de lado, un fuerte programa de inversión a nuevos proyectos de exploración en donde la región (13\%) durante el 2018 se localizaba entre los tres primeros departamentos junto a Cajamarca (32\%) y Arequipa (12\%) con los montos de inversión más elevados a nivel nacional (MINEM, 2019) y con un total de $21.7 \%$ de territorio concesionado para la actividad minera (ver figura 2) (OCM, 2018).

\section{Figura 2}

Estado de la superficie de concesiones mineras en Puno-2018.
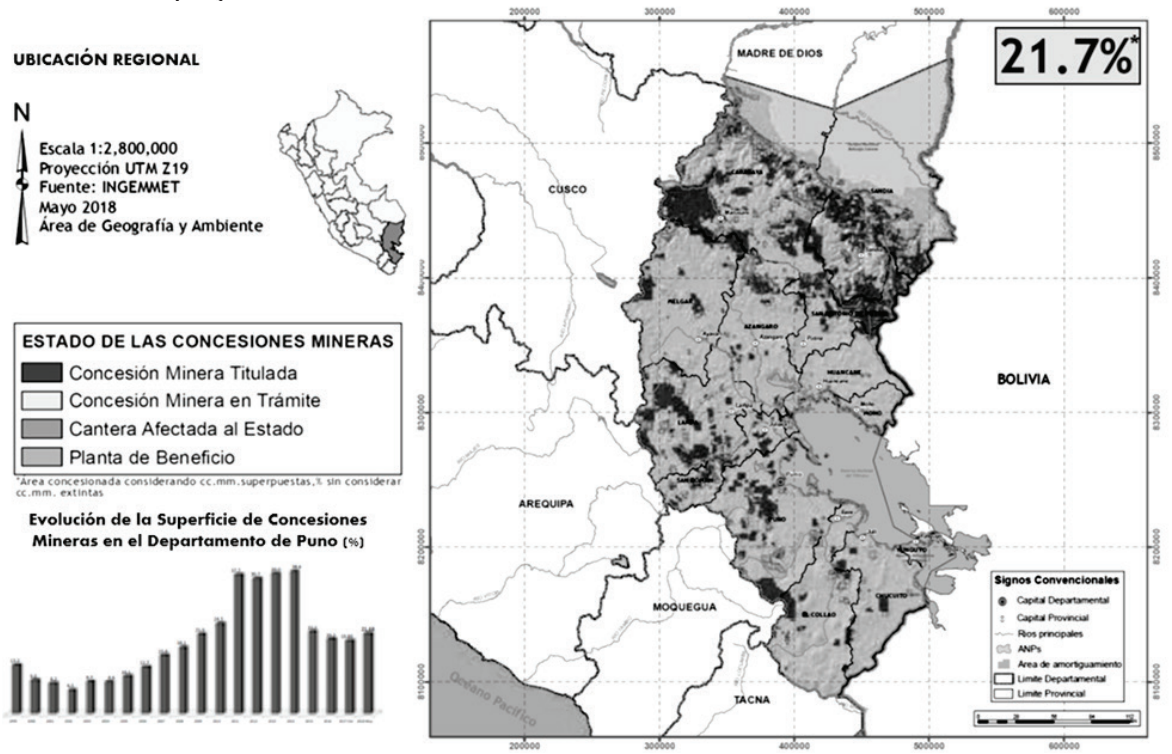

Fuente: OCM (2018a, p. 59).

En la misma magnitud, aunque el modelo actual este concentrado en los denominados metales clásicos. Durante los últimos años, la región 
Puno se ha posicionado una vez más en una zona estratégica debido, especialmente, a la presencia ingente de dos metales del futuro, como los son el uranio y el litio (Mayer y Vásquez, 2018; Cordano, 2018). Sobre este último, es imposible no pensar que la vigilia, el recortado tiempo y las miradas económicas de colosales compañías externas y Estados geopolíticamente poderosos estén y no se aparten de uno de los yacimientos de "oro blanco" más grandes encontrados recientemente en el planeta.

\subsection{Despliegue metodológico}

Dentro de la consideración preliminar, con la finalidad de esclarecer una realidad inmediata y sobre aquellas mutaciones multidimensionales que exterioriza la región a consecuencia del avance desenfrenado de un modelo económico extractivo preponderante. El trabajo comprende tres etapas definidas:

- Primero. Se realizó un análisis preliminar del contenido, es decir, una aproximación casi exacta de la situación por la cual atraviesa la economía regional sobre un anclaje consagrado en gran parte a los recursos minerales. Dicha información pudo canalizarse mediante el acceso oportuno de los informes presentados por la Comisión Económica para América Latina y el Caribe (CEPAL); el Banco Central de Reserva del Perú (BCRP); el Instituto Nacional de Estadística e Informática (INEI); la Dirección Regional de Educación Puno (DREP); la Autoridad Nacional del Agua (ANA); el Ministerio de Comercio Exterior y Turismo (MINCETUR); el MINEM; así como también, en último caso, se validaron los aportes del OCM y la Defensoría del Pueblo (DP).

- Segundo. Definitivamente, en el orden en que el estudio es de corte descriptivo-no probabilístico e interpretativo, los referentes se ven resumidos en unidades de análisis presentados por artículos, informes, documentos y libros. Todo ello, inscritos en un marco de revisión bibliográfica. Igualmente, se optó a raíz de un análisis de los resultados, por emprender una serie de discusiones bajo dos ejes temáticos: (1) Condenados a la minería; y (2) Puno en la cadena de explotación minera. Ambas secciones, sin duda, interesaron para dar un soporte sólido a las pre-formativas 
que presenta la región Puno en un contexto de economía-mundocapitalista.

- Tercero. Por último, el realizar un firme desarrollo y un buen desenlace, presumió entre muchas otras cosas, la revisión exhaustiva de una serie de teóricos e investigadores signados en la cuestión de estudio. Por ello, la búsqueda tuvo como fuente la base de datos: Scopus, WoS, Thomson Reuters, SciELO, Redalyc, Dialnet y Latindex. Sin embargo, dada las limitaciones acerca de estudios micro confabulados sobre la región Puno, igualmente se consideró periódicos, tanto en sus versiones electrónicas como impresas de alcance regional (Diario Los Andes, Sin Fronteras) y nacional (El Comercio, Andina).

\section{Resultados y Discusión}

\subsection{Condenados a la minería}

En los años de la segunda centuria, tras el incremento de los precios de materia prima y la demanda exclusiva de metales a nivel mundial en los diferentes sectores de consumo (Tamayo, Salvador, Vásquez y Zurita, 2017), la irrupción de la minería transnacional ha desplegado focos de inversión en territorios y espacios latinoamericanos. Siendo este, uno de los mayores cinturones de flujo económico donde las cuantiosas superficies concesionadas por la inversión minera fijan a Chile (41.00\%), Perú (14.65\%) y México (11.30\%) como los mayores países en cifras y de crecimiento por exploración, explotación, beneficio y refinación minera (ver tabla 1) (Martínez, 2018).

Este fenómeno de evolución y crecimiento exponencial de territorios concesionados dentro de la línea de producción, inversión y exportación de la actividad minera metalífera ha sido alentado, sin lugar a dudas, por un derrotero motor de domino externo y un conjunto de elementos entrelazados. Entre los cuales destacan: las transformaciones jurídicas en el sector minero (Huwiler, Godfrid y Duárez, 2015), la intervención directa de agentes económicos globales (Banco Mundial) en asesoramientos destinados a abrir el mercado y reducir el control en casi la totalidad de América Latina (AL); aumentando a este arranque de superciclo minero, 
una serie de gobiernos neoliberales que reformaron y sofisticaron la base de un marco legal para promover la inversión extranjera directa. Superponiéndose así, la presencia teórica y práctica de un capitalismo irreconocible en todas las facetas de la economía territorial (Murillo y Sacher, 2017).

Tabla 1

Territorios concesionados por actividades mineras en América Latina.

\begin{tabular}{llll}
\hline País & $\begin{array}{l}\text { Total de hectáreas } \\
\text { concesionadas a la minería }\end{array}$ & $\begin{array}{l}\text { Porcentaje de territorio } \\
\text { concesionado a la minería }\end{array}$ & Fecha del dato \\
\hline Argentina & 18.300 .000 ha & $6,55 \%$ & 2016 \\
Bolivia & 2.285 .583 ha & $2,08 \%$ & 2013 \\
Chile & 31.183 .231 ha & $41,00 \%$ & 2013 \\
Colombia & 5.292 .165 ha & $4,63 \%$ & 2012 \\
Ecuador & 772.729 ha & $2,87 \%$ & 2016 \\
Guatemala & 527.984 ha & $4,85 \%$ & 2017 \\
Honduras & 184.754 ha & $1,64 \%$ & 2017 \\
México & 22.100 .000 ha & $11,30 \%$ & 2017 \\
Nicaragua & 1.194 .909 ha & $9,17 \%$ & 2015 \\
Perú & 18.830 .090 ha & $14,65 \%$ & 2017 \\
\hline
\end{tabular}

Fuente: Martínez (2018, p. 38).

Infaliblemente, la gran riqueza de recursos que presentan estos países, sumado a la flexibilidad en la legislación minera y la tolerancia de las políticas de gobierno en cuanto al ingreso de capitales extranjeros, han hecho que se incentive de manera exponencial la actividad minera en dichas regiones de AL (Saade, 2013). Un caso exclusivo es Perú, país que cuenta con un catálogo de yacimientos mineros que lo ubican dentro del Top 10 de las principales economías del mundo que producen y explotan minerales, asumiendo a este, como el segundo productor de cobre y plata en el planeta; además de ocupar el tercer lugar en explotación de estaño y zinc; cuarto en molibdeno y sexto en oro (MINEM, 2017).

De modo que, tales atributos lo posicionan con una producción metálica de gran inventario que según el Servicio Geológico de los Estados Unidos (USGS), podrían durar varias décadas sobre un cuadro capitalizador extractivo que ha significado (MINEM, 2017) durante años para la 
economía peruana redefinir el rol del Estado y las relaciones sociales en un escenario de procesos de apertura económica, de reformas estructurales y de paradigmas funcionales coligados al capital nacional y extranjero (Tamayo et al., 2017).

En ese orden de ideas, iniciado 2018, según el MINEM, la actividad minera prevé la construcción de 12 proyectos que involucrarían una inversión conjunta de 14,746 millones de dólares, así como de otras que vienen en camino (Ninahuanca, 2018). Sin embargo, como ya se ha explicado con anterioridad, la creciente expansión minera está asociado desde ya, a un incremento sustancial de conflictos socio-ambientales (CSA) que en su mayoría están direccionados por el manejo inadecuado e insostenible de recursos naturales (Barraza, 2006) y de efectos contrarios al bienestar de la población.

Ejemplo de ello, es Perú, que según el informe de la DP, durante el mes de junio de 2017 se registraron alrededor de 177 conflictos sociales, de los cuales, el $72.9 \%$ fueron de carácter socioambiental vinculados a actividades mineras (64.3\%) como hidrocarburíferas (13.2\%) (CEPAL, 2018). Sobre ese punto, según declara el OCM (2018a), los datos expuestos al año siguiente por la DP y el Sistema de Monitoreo de Conflictos Sociales (SIMCO), confinaban de un total de 198 conflictos sociales a las regiones de Ancash (14.1\%) y Puno (9.6\%) como los departamentos con mayor registro de casos y dentro de ellos, de alcance conflictivo socioambiental y de otras índoles (ver tabla 2).

En esa dimensión, el incremento sostenido y generalizado de movimientos y protestas sociales tiene consigo una larga historia en el repertorio de acciones políticas y de puntos de inflexión tanto en países en desarrollo como en democracias consolidadas. Y de hecho, durante las últimas décadas los movimientos sociales se han presentado como elementos esenciales en el rediseño de sociedades modernas, en muchos casos, como herramientas potentes que permean la capacidad institucional del Estado mediante influjos políticos sobre la implementación y el desarrollo de políticas gubernamentales. Incrementando así, su enorme participación en los diferentes estamentos sociales, políticos, culturales, ambientales y económicos (Velázquez, Somuano y Ortega, 2018). 
Problemas en el Sur: Puno en los Procesos de transformación del Capitalismo Global

\section{Tabla 2}

Perú: conflictos sociales registrados en mayo de 2018.

\begin{tabular}{|c|c|c|c|c|}
\hline Región & Total & $\%$ & Activo & Latente \\
\hline Total & 198 & 100.00 & 146 & 52 \\
\hline Ancash & 28 & 14.1 & 19 & 9 \\
\hline Puno & 19 & 9.6 & 14 & 5 \\
\hline Apurímac & 14 & 7.1 & 10 & 4 \\
\hline Cusco & 14 & 7.1 & 11 & 3 \\
\hline Cajamarca & 13 & 6.6 & 12 & 1 \\
\hline Piura & 12 & 6.1 & 8 & 4 \\
\hline Loreto & 11 & 5.6 & 10 & 1 \\
\hline Ayacucho & 11 & 5.6 & 3 & 8 \\
\hline Junín & 8 & 4.0 & 5 & 3 \\
\hline Arequipa & 8 & 4.0 & 7 & 1 \\
\hline Multiregión & 6 & 3.0 & 6 & 0 \\
\hline Moquegua & 6 & 3.0 & 5 & 1 \\
\hline Huánuco & 6 & 3.0 & 5 & 1 \\
\hline Lima Provincias & 5 & 2.5 & 2 & 3 \\
\hline La Libertad & 5 & 2.5 & 4 & 1 \\
\hline Lambayeque & 5 & 2.5 & 4 & 1 \\
\hline Pasco & 5 & 2.5 & 4 & 1 \\
\hline San Martín & 5 & 2.5 & 5 & 0 \\
\hline Lima Metropolitana & 4 & 2.0 & 3 & 1 \\
\hline Amazonas & 3 & 1.5 & 2 & 1 \\
\hline Nacional & 3 & 1.5 & 3 & 0 \\
\hline Madre de Dios & 2 & 1.0 & 1 & 1 \\
\hline Ucayali & 2 & 1.0 & 2 & 0 \\
\hline Huancavelica & 2 & 1.0 & 1 & 1 \\
\hline Ica & 1 & 0.5 & 0 & 1 \\
\hline Callao & 0 & 0.0 & 0 & 0 \\
\hline Tacna & 0 & 0.0 & 0 & 0 \\
\hline Tumbes & 0 & 0.0 & 0 & 0 \\
\hline
\end{tabular}

Fuente: OCM (2018a, p. 5). 
Además, grosso modo, tales protestas sociales son ordinariamente apoyadas por coaliciones de grupos intersectoriales y de clase, que hacen usanza de una extensa gama de narrativas, estrategias y diplomacias para la movilización de sus propias demandas al terreno estatal. Una de esas disyuntivas, se ve traducido en la necesidad reinante de realizar una consulta popular minera, cuyos impactos radiquen en una amplia dinámica demográfica que influya radicalmente en la agenda política y de criterios institucionales. Abriendo de esta manera, la posibilidad de dar paso a nuevos escenarios y espacios de diálogo, debate y participación democrática en el que quede cristalizada, la intervención de una población afectada por la explotación de recursos mineros (Dietz, 2018).

Sobre este asunto, una contrapartida al genuino desarrollo económico atado a rentas extractivas de recursos naturales consiste en la diversificación productiva y de un cambio estructural que desacople la progresiva dependencia de una economía nacional sustentada en sectores extractivos por una que contemple un desarrollo sostenible mediado por marcos de participación social. De igual forma, esto exige impulsar una mayor intervención estatal que visualice de manera estratégica mecanismos de trasparencia e información pública sobre la extracción de recursos naturales, promoviendo el control social, principios de justicia y democracia en su manejo. Todo ello, también involucra desarrollar una sólida capacidad institucional en gestión pública y de gobernanza de recursos naturales que amortigüen el escalamiento y las variadas gradaciones de conflictos sociales (Bielschowsky y Torres, 2018).

Sobre estas circunstancias, las dos miradas que se tienen actualmente acerca de las condiciones en las que se va asentando el Perú sobre un modelo de desarrollo económico extractivo-exportador. Datan por un lado, que durante la última década el país viene experimentado un histórico crecimiento económico sostenido; y la determinante ha sido, la minería, sector considerado como una de las principales columnas vertebrales y promotoras del desarrollo de la economía nacional debido a la gran inversión realizada en este sector (ver tabla 3), que por sus impactos adyacentes, se ha categorizado como el generador de la expansión de inversión pública y del desarrollo económico-social del país (Ramírez, 2015). 
Tabla 3

Perú: inversiones mineras (US\$) por región.

\begin{tabular}{|c|c|c|c|c|}
\hline \multirow[b]{2}{*}{ Región } & \multicolumn{4}{|c|}{ Enero-Febrero } \\
\hline & 2017 & 2018 & Var. $\%$ & Part. \% \\
\hline Tacna & $30,916,778$ & $76,081,544$ & $146.08 \%$ & $14.48 \%$ \\
\hline Arequipa & $76,537,782$ & $69,415,594$ & $-9.31 \%$ & $13.21 \%$ \\
\hline Cajamarca & $20,176,505$ & $42,735,148$ & $111.81 \%$ & $8.13 \%$ \\
\hline Ica & $10,935,751$ & $42,526,755$ & $288.88 \%$ & $8.09 \%$ \\
\hline La Libertad & $28,266,411$ & $39,917,089$ & $41.22 \%$ & $7.60 \%$ \\
\hline Junín & $37,056,424$ & $37,591,609$ & $1.44 \%$ & $7.15 \%$ \\
\hline Moquegua & $27,428,827$ & $34,535,257$ & $25.91 \%$ & $6.57 \%$ \\
\hline Áncash & $26,891,664$ & $32,072,094$ & $19.26 \%$ & $6.10 \%$ \\
\hline Lima & $18,658,930$ & $29,434,260$ & $57.75 \%$ & $5.60 \%$ \\
\hline Cusco & $82,227,080$ & $26,460,909$ & $-67.82 \%$ & $5.04 \%$ \\
\hline Puno & $7,669,019$ & $23,648,529$ & $208.36 \%$ & $4.50 \%$ \\
\hline Huancavelica & $4,536,718$ & $18,243,113$ & $302.12 \%$ & $3.47 \%$ \\
\hline Pasco & $17,110,385$ & $16,995,000$ & $-0.67 \%$ & $3.23 \%$ \\
\hline Ayacucho & $7,793,898$ & $14,785,950$ & $89.71 \%$ & $2.81 \%$ \\
\hline Apurímac & $25,490,545$ & $13,058,736$ & $-48.77 \%$ & $2.49 \%$ \\
\hline Huánuco & $2,050,458$ & $3,219,914$ & $57.03 \%$ & $0.61 \%$ \\
\hline Piura & 819,685 & $2,431,212$ & $196.60 \%$ & $0.46 \%$ \\
\hline Madre de Dios & $1,133,935$ & $1,879,252$ & $65.73 \%$ & $0.36 \%$ \\
\hline Amazonas & 54,289 & 230,200 & $324.03 \%$ & $0.04 \%$ \\
\hline Callao & 51,200 & 180,000 & $251.56 \%$ & $0.03 \%$ \\
\hline Lambayeque & 5,963 & 10,100 & $69.37 \%$ & $0.00 \%$ \\
\hline San Martín & 1,039 & 120 & $-88.45 \%$ & $0.00 \%$ \\
\hline Tumbes & 3,000 & 20 & $-99.33 \%$ & $0.00 \%$ \\
\hline Loreto & 58,000 & - & $-100.00 \%$ & $0.00 \%$ \\
\hline Total & $425,874,287$ & $525,452,403$ & $23.38 \%$ & $100 \%$ \\
\hline
\end{tabular}

Fuente: MINEM (2018, p. 25).

Dentro de ese reforzamiento y expandida inversión, las proyecciones potenciales al 2050, estiman al cobre (69\%) con una producción acumulativa de 320 millones de toneladas finas como el metal de mayor aporte económico para el Perú, seguido del oro (10\%), zinc (7\%), hierro (6\%), 
plata (5\%), molibdeno (2\%), plomo (1\%) y otros (1\%). Siendo además, Apurímac, Cajamarca, Áncash, Arequipa y Moquegua, las regiones con el mayor canon minero sobre el cual pesan estas riquezas minerales (Chira, Ríos, Trelles y Villareal, 2018).

En esa línea, para Ramírez (2015), una primera impresión nos lleva a pensar que la minería en Perú tiene un rol valioso en el proceso de evolución regional y de integración de los pueblos más alejados del territorio nacional, pues desde de siempre, se ha caracterizado por ser un promotor del desarrollo. De allí, "la importancia de promover la inversión minera responsable dentro de un marco de inclusión social con el objetivo de garantizar un mayor bienestar para su población y reducir la pobreza" (Ramírez, 2015, p. 200). No obstante, de otro lado, estas mismas dinámicas económicas extractivas de imbricaciones territoriales-ambientalesglobales hacen posible transformar y reconfigurar la vida de muchos pueblos a relatos de confrontaciones y de resistencia frente a escenarios de apropiación y despojo patrimonial, de una lucha que amerita revertir las desigualdades socioambientales y del reconocimiento de derechos quebrantados (Ulloa, 2016).

Desde esa perspectiva, la otra imagen que se tiene, es que los ajustes de este modelo de desarrollo vienen desencadenando una serie de CSA en comunidades ubicadas en territorios ricos en recursos naturales (Valencia, 2013). Tales signos de conflictividad, según sugiere Saade (2013), se deben principalmente a que las causas están asociadas a impactos ambientales, problemas territoriales, a la falta de consulta previa, a la vulneración de derechos humanos, y finalmente -interminable por supuesto-, a una enérgica obtención de beneficios por parte de tres grandes agentes colisionantes: el Estado, las empresas y las comunidades, considerando casi siempre a este último, con ciertas desventajas en su punto de partida (debido a sus condiciones) y en el proceso de explotación de los recursos mineros (y de cómo se redistribuye la riqueza del mismo).

Para agregar ese armazón, en Perú, desde el 2008 los análisis en cuanto a conflictos sociales gira en torno a asuntos de gobierno local, regional, nacional, socioambiental, por demarcación territorial, por cultivo ilegal de hoja de coca, laborales, comunales, electorales, entre otras cuestiones. Del mismo modo, cabe indicar también que mediante la Resolución 
Ministerial $N^{\circ}$ 161-2011-PCM, los lineamientos y estrategias de gestión de conflictos, precisan que la naturaleza destructiva o conflictividad social puede ser categorizado en: ambientales; minero-energético e industriales; hídricos; infraestructura; gestión de bienes y recursos públicos; agropecuarios; laborales y territoriales (DP, 2016). Siendo de todos ellos, los CSA los más acuciosos por su alcance desde los años 90 (Huamaní, Macassi, Galarreta y Rojas, 2012).

Además, Huamaní y otros (2012), a través de un estudio sistemático de las causas por las cuales se gestan y extienden sin discreción alguna los CSA, identifican entre otros factores contribuyentes aquellos que están estrictamente asociados a los imperfectos estructurales, institucionales, de intereses, a una ilegible información, a la limitada comunicación, la desconfianza y, en última, a una idiosincrasia de las partes de quienes buscan en los recursos naturales su apoderación completa y de quienes son afectados en gran medida por las mismas maquinarias del modelo neoliberal neo-extractivo.

En todo caso, el paraje aquí, es que el modelo de desarrollo económico global opera fundamentalmente, en formas de acumulación por desposesión y control, que no solo son agenciados y obedecen a empresas multinacionales, sino también promovidas, garantizadas y patrocinadas por algunas instancias estatales que, en un tiempo próximo acaecen en la aparición de CSA como consecuencia de una descomunal malformación de relieves, daños ecológicos irreparables, propiedades colectivas afectadas, identidades patrimoniales subsumidas y de derechos humanos vulnerados a pueblos indígenas y comunidades campesinas (Valencia-Hernández, Muñoz-Villarreal y Hainsfurth, 2017).

En efecto, en Perú las variadas formas en las que se agitan los conflictos sociales entre las unidades productoras (empresas) y las sociedades contiguas a la concesión, y como mediador de dichos aprietos el Estado, se derivan en contradicciones en el que muchas veces terminan en la desconfianza por las instituciones gubernamentales, en la represión por parte del gobierno a los grupos sociales con medidas centradas en la violencia y el temor, y que en casos extremos, cesa en la criminalización de la protesta de quienes se oponen y son más sensibles a los proyectos de gran envergadura. 
De esta forma, el modelo de seguridad humana, axioma de dimensión mundial que fluye desde enormes aparatos e instituciones internacionales corre un gran riesgo, no solo por el momento y las condiciones actuales del capitalismo global y de una red de nudos criminales deliberadas del modelo extractivista, sino que también por la misma agencia estatal que dice combatir los problemas de violencia e inseguridad, aunque a menudo, tiende a empeorarlos. De esto, para Gledhill (2017), las políticas de "segurización" implementadas por el Estado, si bien supone una alternativa para poder intervenir en los conflictos sociales y de aquellos desmanes provocados por grandes corporativos transnacionales superpuestos en la idea cardinal de esparcir las utilidades al máximo, acaban favoreciendo impensablemente a estos últimos.

Es en esta lógica que se debe de cuestionar al actual y extendido modelo de desarrollo económico global, cuyas disrupciones rebasan en absoluto, ambientes, recursos y las condiciones de vida de emporios poblacionales cuestionados por los impactos en la biósfera y de aquellas amenazas motivadas por la injusticia socioambiental. Letrado y entendido así el problema, es que se exige desde los diferentes ecosistemas, soluciones socioambientales integrales contra una fuerza exógena de cuantiosos capitales (Challenger, Córdova, Chavero, Equihua y Maass, 2018) sistemáticamente criticados por sus bondades en materia de políticas públicas y de sus efectos perversos en el orden social (Torres, 2001) cuyas formas de incluir a los excluidos significa, darles un lugar adentro pero al margen, una receta útil "para asegurar el proceso de acumulación capitalista y evitar conflictos sociales y confrontaciones violentas" (Domenech, 2007, p. 71).

\subsection{Puno en la cadena de explotación minera}

En lo que va de los años, según el MINEM (2017), la fuerte concentración de producción metálica en 2016 fijaban en primer orden a la región de la Libertad con el $28.7 \%$ de la producción total de oro en el país, seguida solamente, de manera muy cercana por Cajamarca; asimismo, el 22.3\% de producción de cobre y el $37.2 \%$ de molibdeno posicionaban en el primer lugar a la región de Arequipa como una de las mayores productoras de estos metales; del mismo modo, la producción de zinc (23.1\%) en Ancash, plomo (27.8\%) en Pasco, plata (20.1\%) en Junín, y el 100\% de estaño y hierro en Puno e Ica respectivamente, hacían notar de estas regiones su 
destacado potencial geológico, así como también, el perfil adecuado para incentivar la inversión minera de grandes capitales transnacionales.

Pese a esto, el radio de influencia de impactos positivos no se ve expresado en regiones como Huancavelica, en donde casi el 50\% de su territorio ha sido concesionado por actividades mineras; de la misma manera, en departamentos como Apurímac (54.44\%), Cajamarca (44.37\%), Áncash (36.1\%) y Ayacucho (26.2\%), regiones que han llegado a alcanzar una alta concentración de empresas dedicadas a la explotación de minerales y otros, que en el largo plazo, lo único que han mostrado fehacientemente son expectaciones de un conglomerado de externalidades negativas producto de sus propias fallas en el proceso de acumulación monopólica. Estos son, solo algunos ejemplos de una extensa lista de espacios geográficos que agencian un alto porcentaje concesionado por las transnacionales, cifras que no se alejan, contrariamente, de una realidad abatida por la pobreza y la desigualdad en cada departamento ya citado, donde casi las 3/4 partes de la población aún mantiene un exiguo acceso a servicios básicos de salud, educación, vivienda, entre otros (Asencios, 2016).

Frente a esta paradoja entre la expansión deliberada de capitales por la actividad minera en la captación de recursos comunes frente a los niveles de pobreza y pobreza extrema existente en estas regiones (Velásquez et al., 2014), sumado a la poca representatividad del Estado en brindar bienes y servicios públicos de forma oportuna a la población y de buscar la equidad de ingresos mediante la formulación de proyectos, programas y políticas sociales. Se anexa un desenvolvimiento de viejas prácticas mineras y del manejo inadecuado de residuos que se generan por una actividad económica de explotación que, ineludiblemente desde siglos atrás, ha originado grandes pasivos ambientales y de arraigo social que durante décadas se han convertido en un caso alarmante al afectar al entorno físico del territorio y de la cadena trófica del ciclo de vida del hombre en zonas que involucran aguas ácidas, bocaminas, botaderos y relaves mineros (Romero et al., 2008).

Sobre este enunciado, los datos indican a que nivel de regiones, Ancash (1251), Cajamarca (1075) y Puno (1050) son los que registran un mayor número de Pasivos Ambientales Mineros (PAMs) que se constituyen de todas maneras en un riesgo potencial de alerta para el ecosistema, la 
salud pública y de quienes son próximos a instalaciones o restos de residuos geoquímicos producidos por operaciones mineras (ver tabla 4). Sin olvidar que en los últimos años, no sólo se han intensificado pasivos ambientales provenientes de formidables concesiones mineras, sino que además, de una pequeña minería y minería artesanal, casos que deberían ser incluidos dentro de los ajustes y de atención en los distintos niveles de gobierno (Red Muqui, 2015). Especialmente, en zonas donde el Estado no ha tenido presencia real y efectiva sobre aquellos capitales de gran amplitud que se desplazan en torno a actividades ilegales e informales de estratificación minera (Ipenza y Valencia, 2014).

\section{Tabla 4}

Evolución del inventario de PAMs por regiones.

\begin{tabular}{|c|c|c|}
\hline Región & $\begin{array}{l}\text { Inventario Inicial } \\
2006\end{array}$ & $\begin{array}{l}\text { Actualización } \\
2015\end{array}$ \\
\hline Amazonas & ---- & 157 \\
\hline Ancash & 133 & 1251 \\
\hline Apurímac & 43 & 149 \\
\hline Arequipa & 42 & 372 \\
\hline Ayacucho & 69 & 98 \\
\hline Cajamarca & 20 & 1075 \\
\hline Cusco & 44 & 581 \\
\hline Huancavelica & 67 & 858 \\
\hline Huánuco & 23 & 313 \\
\hline Ica & 31 & 124 \\
\hline Junín & 51 & 637 \\
\hline La Libertad & 14 & 510 \\
\hline Lambayeque & 8 & 4 \\
\hline Lima & 60 & 613 \\
\hline Madre de Dios & 22 & 22 \\
\hline Moquegua & 53 & 137 \\
\hline Pasco & 40 & 454 \\
\hline Piura & 18 & 24 \\
\hline Puno & 79 & 1050 \\
\hline San Martín & 1 & 1 \\
\hline Tacna & 32 & 186 \\
\hline Total & 850 & 8616 \\
\hline
\end{tabular}

Fuente: Red Muqui (2015, p. 16). 
En estas circunstancias, pese a la existencia de normativas nacionales e internacionales que protegen al medio ambiente y a entornos sociales más vulnerables, el impacto multidimensional se ve irradiado en la enorme contaminación a cientos de cuencas hidrográficas, lagos, lagunas; áreas protegidas, de cultivo, ganadería y pesca; así como la modificación de paisajes, campos y ciudades afectadas por relaves mineros. Tal situación ha meditado que, mientras el capital y la acumulación indisoluble de recursos se expanden, al mismo ritmo, la profanación de las tierras y el agua son acompañados por numerosos conflictos entre comunidades y empresas por el control y acceso de estos recursos (Ramírez, 2015).

Así, se tiene que, una inmensa cartera de proyectos enfrenta dificultades en su diligencia operativa, una tras otra, se van quedando aplazados como si fueran elefantes blancos de enormes inversiones sin movimiento o quedasen inconclusas tras una poderosa financiación. Entre las que destacan, según el monto de inversión y del movimiento de capitales han sido: Conga, proyecto valorizado en 4,800 millones de dólares, que es manejado por Yanacocha en la región de Cajamarca; este, fue suspendido en 2011 tras una serie de protestas y demandas sociales que incluían afectar la cuenca hidrográfica de la región. Otro proyecto que acabó mal fue Cañariaco (Lambayeque), proyecto de gran escala que a pesar de que la empresa Candente Copper apreciará enormes beneficios para la población, este liquidó en 2013. En ese camino, el destino no fue distinto para con otros dos proyectos: Río Blanco y Tía María, ambos proyectos mineros con una inversión aproximada a 1,500 millones y 1,400 millones de dólares correlativamente, se vieron asfixiados ante un conflicto que terminó aplastando el desarrollo normal de ambas minas en Piura y Arequipa (Falen, 2016).

El cuestionamiento parte entonces, de una población con fuertes lazos de sentido común histórico-territorial que ha introducido desde las denominadas fronteras, elementos constitutivos de lucha por la defensa de la tierra, de la condición humana y del reconocimiento de una justicia socio-ambiental frente al desempeño degradante de proyectos e irregulares concesiones que han significado ser una amenaza latente a través de la contaminación de fuentes de agua, el deterioro del aire, la degradación de suelos, de efectos contrarios en la salud pública, la desaparición de flora y fauna, la desestructuración de instituciones comunales, y demás cuestiones que quedan por discutir y de no terminar. 
Todo, sin duda, mecánicas asociadas a una visión occidental que presupone el domino completo sobre el ecosistema y de las diversas formas organizativas del mundo de la tierra-oikos-pacha (Bravo, 2009). Una realidad capitalizadora de bienes compartidos que implica entre muchas otras cosas, costos ambientales, sociales, económicos y de tensiones que van desde las formas desiguales que va edificando en la multi-realidad hasta las resonantes ondas de conflictos sociales y medioambientales que surgen, definitivamente, por un patrimonio cultural y territorial atravesado por relaciones de poder que han consumado por extenderse desde sectores hegemónicos a campos abiertamente vulnerables y mutables (Mariano y Endere, 2017).

Hasta aquí, un análisis muy en particular nos conduce a visualizar las pre-formativas de la región Puno en un marco de economías globales subvencionadas por el capital. No obstante, para encaminar y afinar esta plataforma, cabe precisar que según el MINCETUR (2018b) durante el 2018, Puno se localizaba entre las 10 regiones más importantes del país en cuanto a dinamismo económico. La misma que tiene una densidad poblacional de $4.5 \%$ y una producción estimada del $2.3 \%$, basada, principalmente en actividades agropecuarias y de un desempeño minero dominante en el mercado mundial (ver tabla 5).

Tabla 5

Puno: sector minería.

\begin{tabular}{|c|c|c|c|c|c|c|}
\hline & & \multirow{2}{*}{$\begin{array}{l}\text { Estructura \% } \\
2015\end{array}$} & \multicolumn{4}{|c|}{ Enero - Diciembre } \\
\hline & & & 2016 & 2017 & Var. \% & Contribución \\
\hline Estaño & (TMF) & 41.5 & 18,788 & 17,791 & -5.3 & -2.3 \\
\hline Plomo & (TMF) & 2.5 & 1,333 & 1,649 & 23.7 & 0.3 \\
\hline Oro & $(\mathrm{kr}-\mathrm{f})$ & 51.9 & 4,522 & 4,102 & -9.3 & -5.0 \\
\hline Plata & (kg-f) & 1.2 & 2,959 & 1,366 & -53.8 & -0.3 \\
\hline Zinc & (TMF) & 2.9 & 1,159 & 864 & -25.4 & -0.4 \\
\hline \multicolumn{3}{|c|}{ Sector Minería 1/ } & -7.7 & & & -7.7 \\
\hline
\end{tabular}

1/ A precios de 2007.

Fuente: BCRP (2017).

En ese entender, cuando se habla dentro de las delimitaciones de la Macro Región Sur (MRS), Puno viene a ser de forma clara, la cuarta región 
de mayor exportación (12\%) de rubros tradicionales (98\%) y no tradicionales. Destacando como eje potenciador de la economía altiplánica, el oro (97\%), seguido de una notoria exportación agropecuaria en quinua, así como también, del envío de pelo fino de alpaca y harina de maca, llegando a exportar en el primer semestre de 2018 un total de 786 millones de dólares, una cifra mucho mayor al año anterior. Igualmente, todo indica que Puno es el primer productor de quinua, papa, fibra de alpaca y estaño del país, así como el tercero en la producción de carne vacuna y una exportación de lana que ha sobrepasado en los últimos años el récord de más de 10 millones de US\$ (MINCETUR, 2018a).

Sin relegar, por otro lado, el crecimiento sostenido del café sin tostar, producto básico alternativo por el cual giran económicamente más de 6,000 familias pertenecientes a los valles de San Gabán y Sandia (Andina, 2018a), que sin tardar, han conseguido llegar a los mercados del Reino Unido, Estados Unidos y Alemania (MINCETUR, 2018a). A este tenor, sobre esta provincia de gran atractivo, reposa también un incesante desarrollo minero explotador y colonizador que lo ha catequizado durante las últimas décadas en un destino clave para la migración y de economía local (Pajuela, 2009).

Por todo lo expresado, queda bastante claro que una de las actividades de mayor alcance productivo y de cadena en Puno, viene a ser la extracción y transformación primaria, en especial, la minería. El enorme potencial que representa este sector refiere que, en 2013 la participación porcentual en el PBI global fue de $11.7 \%$. Una exportación regional de minerales que ha ascendido a 42,177 millones de US\$ (DREP, 2015). Siendo los productos mineros como el oro (US\$ 29,7 millones), plomo (US\$1,0 millones), cobre (US\$ 0,3 millones) y estaño (US\$ 0,1 millones) con los mayores niveles de exportación, y que representaron el $98.8 \%$ del total de productos tradicionales exportados por el departamento durante ese año (ver figura 3) (BCRP, 2013).

Del mismo modo, la exportación de productos no tradicionales, es decir, agropecuarios, pesqueros, textiles y minerales no metálicos, simbolizaron un total de 1,6 millones de US\$ correspondientemente. Siendo uno de los principales destinos de exportación, Europa (86.1\%) y el continente asiático (11.0\%) (BCRP, 2013). 


\section{Figura 3}

Puno: sectores productivos que más aportan a la economía regional-2018.

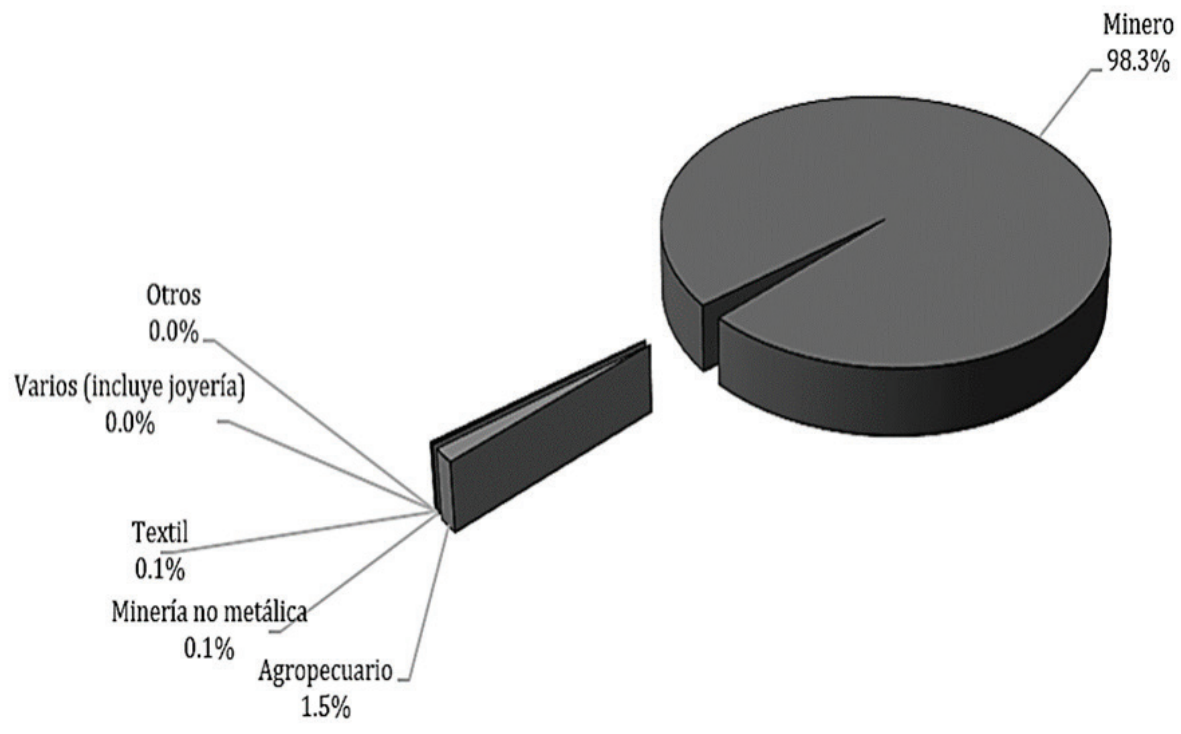

Fuente: MINCETUR (2018b, p. 2).

Tales magnitudes de desempeño económico para 2017, tampoco se vieron desestimados, a pesar de algunas irrupciones en el mercado de exportaciones de productos tradicionales y no tradicionales que implicaron su disminución. Estas, terminaron en diciembre del mismo año sumar un total de 165,1 millones de US\$ en exportación de productos como el oro, estaño, fibras textiles, materiales de construcción, cemento, quinua y trucha congelada. Para el cierre del año (enero a diciembre), su valor había alcanzado 1,925,2 millones de US\$, constituyendo a los mercados de la India (45.1\%), Suiza (20.4\%), Estados Unidos (14.4\%), Emiratos Árabes Unidos (8.9\%), Países Bajos (2.9\%) y Japón (1.3\%), como los principales bloques de destino económico para la región Puno (BCRP, 2017).

De esta manera, después de un crecimiento del 5\% en $2017,59 \%$ en 2016 y $135 \%$ en 2015. No se hizo esperar que en 2018, las exportaciones de Puno continuaran aumentando en $9.7 \%$, resultado que ha obedecido a las mayores exportaciones del sector agropecuario (+41\%), minero $(+10 \%)$ y textil $(+9 \%)$, jugando un papel significativo, la India $(+72 \%)$, 
Italia (+4002\%), Malasia (+817\%) y Turquía, principales destinos; que han conllevado a la expansión de fuertes capitales y al desenvolvimiento económico de empresas como Minerales del Sur (10.4\%), Comercializadora de Metales Luz (8.1\%), Trading Express Gold (7.2\%), A.L. Copacabana (4.9\%) y Aurimetal (4.1\%) (MINCETUR, 2018b).

En esa extendida ruta, el oro ha sido, sin duda alguna, uno de los mayores elementos metálicos que ha involucrado el crecimiento en los niveles de exportación (97.7\%), así como la quinua, la lana, el pelo fino de alpaca y la trucha, productos que consiguieron ser canalizados por países como la China (+3075\%), Canadá (+192\%) y Uruguay (+83\%). En gran medida, las anteriores dinámicas representaron tanto para la oferta y la demanda de mercado de la región sureña del país una oportunidad y apertura completa hacia el mercado internacional, toda vez que significara el comienzo de nuevos desafíos postremos para la economía local y de su regular mantenimiento de competitividad en la escala transnacional (MINCETUR, 2018b).

En efecto, para seguir perfilando, durante ese año la amplia gama de producción agropecuaria, especialmente la minera, ha recibido una inversión de casi 33 millones de dólares (3.96\% del total nacional). Así también, el eslabón de una cartera de proyectos mineros que han sumado una inversión calculada en 1,281 millones de US\$, un paquete económico distribuido en proyectos como Corani, Ollachea, Minsur San Rafael, Macusani y de otros 4 proyectos que aún se mantienen en exploración. Haciendo de la meseta altiplánica, una superficie concesionada que sobrepasa el $21.68 \%$ de todo el territorio regional $(1,471,771$ hectáreas) (ver figura 4) (OCM, 2018a).

Sin embargo, esta misma expansión ha demandado una evolución constante de conflictos sociales que han puesto en el ojo de la tormenta a la altiplanicie con 18 conflictos. De estos, 12 exclusivamente de tipologías socioambientales (66\% del total), y de ellos, 9 afines a la gran y mediana minería, así como también, de la pequeña minería informal. Un dato histórico que posiciona en el segundo lugar a Puno a nivel nacional con los mayores índices de casos de CSA registrados al 2018 (OCM, 2018a). 
Figura 4

Perú: superficie departamental ocupada por concesiones mineras-mayo 2018.

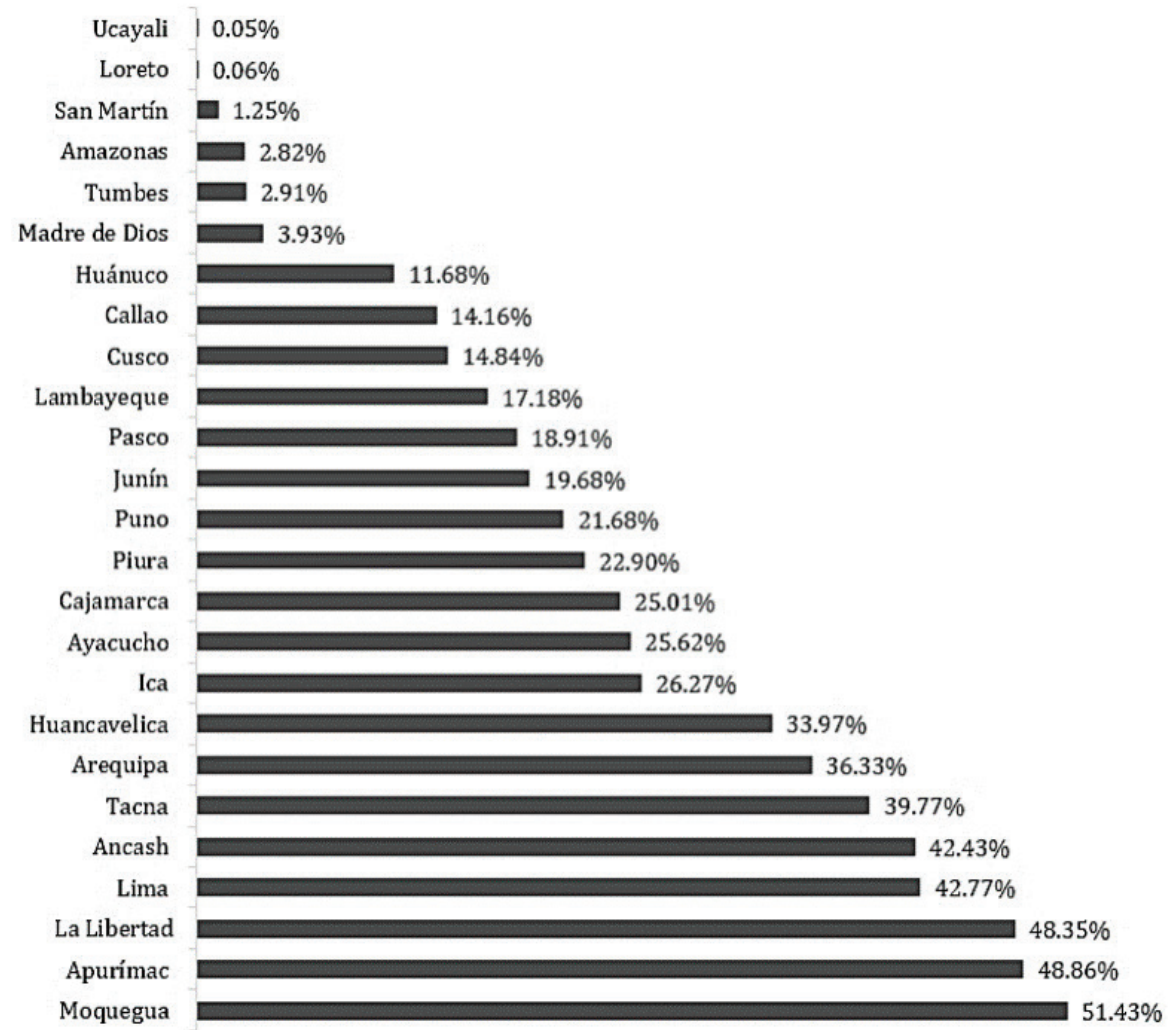

Fuente: OCM (2018a, p. 10).

Sobre esta base, es correcto mencionar que gran parte de los CSA en Puno vienen cargados de una fuerte contaminación a cuencas hidrográficas, que son, en su mayoría de uso agrícola, ganadero y de consumo humano. Uno de estos casos, aún pendiente por supuesto, se ubican en la provincia de Melgar, en donde los pobladores de Huamachiri, Cupi, Ayaviri y Llalli solicitaron a la ANA, al Ministerio del Ambiente (MINAM) y al MINEM el retiro inmediato; además de la sanción correspondiente a la empresa minera Aruntani, acusada de un daño irreparable a la cuenca Llallimayo, así como el cese del uso de agua en la cuenca de Hatun Ayllu que trajo desde el 2015 una serie de reclamos por parte de la población (OCM, 2018a). 
A la par, otros conflictos relacionados estrechamente con el agua, es la protesta de una gran masa de indignados en contra de las acciones de la minera Arasi S.A.C. de Aruntani, denuncias y demandas sobre una permanente contaminación del río Chacapalca, río de consumo diario en donde se habría identificado metales como arsénico, manganeso, plomo y mercurio. Conflicto que en el tenso camino ha originado movilizaciones por parte de los comuneros durante meses, además de responsabilizar al Organismo de Evaluación y Fiscalización Ambiental (OEFA) por su inactividad. En la misma línea, otro proyecto minero que se ha visto opacado por tercera vez durante los meses de febrero, marzo y abril por posibles daños en contra del medioambiente y de un temor absoluto en la población que yace en la catastrófica imagen de deterioro para el sector agropecuario ha sido Santo Domingo de Minsur, proyecto que opera en el distrito de Nuñoa (Melgar). Ahí, en un cuadro de protestas y miedos, la población pide y exige espacios de diálogo en donde se puedan mediar de la mejor manera la incursión de concesionarias que respeten los recursos disponibles de la naturaleza (OCM, 2018a).

En otro extremo, no resulta extraño que en el centro poblado minero artesanal la Rinconada (5200 msnm). Lugar, como indican Goyzueta y Trigos (2009), habitan y se mueven más de 35,000 personas a diario (un dato variable a la actualidad). Donde el $83.3 \%$ se dedican exclusivamente al proceso de extracción de oro y el resto a actividades comerciales para su desarrollo y supervivencia en la zona. Así también, la fuerte incidencia de la población (89\%) en el consumo de fuentes hídricas provenientes del lago Cumuni y del deshielo de la zona denominada Riticucho. Uno y otro, con altos niveles de contaminación que ponen en riesgo la salud pública de muchos lugareños de las regiones gélidas de Puno. De esta forma, la Rinconada cuenta con un dinamismo poblacional de altura que se desenvuelve y se ve expuesto dentro de un problema de contaminación ambiental generada por la actividad minera informal y la sobreexplotación insostenible del oro y del manejo inadecuado y exagerado del mercurio para su extracción (Cely-Andrade, García-Ubaque y Manrique-Abril, 2017).

Es en ese contexto, que la minería artesanal, ante la ausencia de agua potable y de servicios de desagüe se presenta como un escenario lleno de riesgos para el conjunto poblacional en términos de calidad de vida y de 
los involucrados a una maldición encadenada al oro, que no solo consigue transformar a miles de personas que buscan la vida a 5000 metros de precariedad, de escombro y basura (Espinosa, 2017) que dañan a un ecosistema de altura, sino también, de fuertes contaminantes y residuos tóxicos que se vierten en los ríos, tomando la apariencia de aguas negras que terminan desembocando cada año a las orillas del Titicaca. Siendo este, un problema más que destruye la flora y fauna de un mágico y glorioso pasado incaico de míticas leyendas (Briceno, 2017).

Un caso similar, es el que se produce en San Antonio de Putina, en donde el "oro, pesa más que la vida" -relata un comunero-. En esa región, los pobladores de la comunidad de Ananea, criadores de camélidos se han visto amenazados por un drama irreparable que ve a lo lejos la usurpación y la muerte de fuentes hídricas, así como la contaminación de los pocos manantiales y de terrenos verdes que quedan por la incrustación de una creciente minería ilegal en la zona. Un hecho, que hace la existencia de escasos pastizales para el ganado, dificultando la pequeña economía de subsistencia de cientos de pobladores poco organizados quienes se encuentran indignados e impotentes al saber que son sus propias instituciones estatales las que les dan la espalda cuando se les hace el reclamo sobre las condiciones que les toca vivir; o, por la inacción de las mismas antes de haber llegado a este punto explosivo (Moncada, 2018).

Para contextualizar y reforzar ese desenvolvimiento, es sobre entendido que en nuestro país la actividad minera se concentra en las cabeceras de cuenca, es decir, en regiones alto-andinas, y es ahí -como manifiesta Castro (2009, p. 22)- donde se originan "mucho de los temores y percepciones de las poblaciones cercanas acerca de la posible contaminación de sus recursos (agua y tierra)". Y que frente a un cuadro de derechos mineros, pobreza y conflictos (Castro, 2013; Canaza-Choque, 2018a), a Puno, se le suma la creciente contaminación del medio ambiente por la minería informal que se desarrolla en el contorno de las cabeceras de los ríos Azángaro, Putina, Ayaviri y Palca, que en consecuencia, genera un gran "movimiento de tierras orientado a la extracción ilegal de recursos mineros llegando a afectar la topología de la zona, ocasionando la alteración de ecosistemas y la pérdida de hábitat para algunas especies" (Tumi y Escobar-Mamani, 2018, p. 242). 
Dentro de ese marco imperante, un ejemplo claro sobre los efectos de la actividad minera en fuentes acuáticas nos expresan Matute, Holgado y Vásquez (2009), quienes señalan que la actividad aurífera emprendida por más de 10 mil pequeños mineros informales en Ananea (Huancané), han sido un punto crítico de daño irreversible para el río Ramis, principal colector del Titicaca, de consumo pecuario, de ámbito rural y de otras actividades que se ven al presente y al futuro afectadas colateralmente. Además, a este problema ecológico se añaden los vacíos legales (Ponce y Jahuira, 2019) y la nula intervención efectiva de acciones emprendidas por entidades locales y regionales de Puno. Términos finales, que suponen un problema más por parte de los gobiernos de turno al no poder canalizar y gestionar de manera eficiente muchos de los problemas suscitados en la región lacustre.

En esa línea, no causa sorpresa que durante el mes de septiembre de 2016 se registrase un nuevo caso de presión ambiental que pone en apuros a la población y autoridades jurisdiccionalmente pertenecientes a las provincias de San Antonio de Putina, Carabaya y Azángaro, quienes se oponen en absoluto a las actividades metabólicas de la minera informal que labora en los distritos de Ananea, Crucero y Cuyo, ya que estos generan una contaminación difusa tanto subterránea como superficial en la cuenca del río Ramis (DP, 2019).

Aquí, sobre esta base, un punto clave es entender que las prolongadas tensiones suscitadas alrededor de fuentes hídricas y de los diversos usos que se dan por diferentes grupos de interés disputados, conducen a incuestionables cánones de conflictividad como consecuencia de una débil gobernanza transnacional, nacional y municipal sobre el manejo integral del recurso acuático en los distintos regímenes territoriales (Stein, 2018).

Así, al no tener presente o la mínima territorialización del Estado en regiones oscuras, pero con considerables fuentes de riqueza, traspone dichas regiones en zonas de sacrificio o peligro (Homazabal et al., 2019; Biocca, 2020). Dado que, desde hace una buena data, empresas capitalizadoras de recursos minerales de gran tamaño, acompañados de Estados poderosos y de favorables marcos jurídicos en tierras periféricas han atinado puntos de inflexión y deterioro territorial insalvable sobre una etapa turbulenta de procesos predestinados a la acumulación de riqueza y de exuberantes tasas de rentabilidad (Berardi, 2013). 
No obstante, paralelamente al impacto protagónico y degradatorio del aparato capitalizador en terrenos aprovechables. Este, en su camino de proyecto impositivo primario no solo va absorbiendo pequeñas, ilegales e informales actividades mineras a una estructura mucho más amplia del que se compone; sino también, en su movimiento ha encontrado insospechadamente un muro de masa humana que busca por completo defender el denominador común de todos, el agua, la tierra y la vida vertida en ella. Contenidos entrelazados que significan para la placa social movida, potencialmente cláusulas que se tienen que respetar, defender y si fuera posible, ir contra un torrente y erosivo daño provocado por el capital extranjero y de sus diminutas redes extractivas. Inclusive, aunque esto implicase la muerte en el campo de batalla (Canaza-Choque, Supo, Ruelas y Yabar, 2020).

En ese itinerario, una peripecia de este tipo enfilado a resguardar el derecho territorial y de altercado contra hegemónico frente a la figura mega-minera presentado en la meseta andina fue Santa Ana. Conflicto suscitado entre autoridades, pobladores y la empresa Bear Creek Mining Company (BCMC), que, de la noche a la mañana, como si fueran ondas sonoras o sísmicas transitaron a escala regional, nacional e internacional sobre cómo terminaría dicho conflicto despertado en el Sur del país.

Pues, como se relató desde un inicio, durante el 2011 se dio eclosión a un grupo antiminero calificado por la prensa nacional y demás, como Aymarazo. Un movimiento de corpus cultural anticapitalista que paralizó durante 45 días los flujos económicos de libre mercado en la región Puno (Comisión de Investigaciones Politai, 2013). Todo esto, a raíz de un proceso lleno de especulaciones, intereses, desconfianza e irregulares que de manera intempestiva acabaron sepultando a la empresa concesionaria BCMC-SP en las alturas de Kelluyo y Huacullani. Una situación que más allá de lo normal, puso en jaque y mate al Estado y al gobierno regional de Puno en el manejo de este inconveniente a 3810 msnm (Pinto, 2013).

\section{Reflexiones Finales/Conclusiones}

Desde hace algunos años, el capitalismo ha desarrollado una serie de engranajes y modernos mecanismos en su propio y adecuado funcionamiento como sistema-mundo, de renovarse cuantas veces quiera ante una falla 
detectada o de una crisis que especule su final terrorífico. Es el capital, primero un factor decisivo y predominante en las diferentes actividades productoras; y a la vez, un poder que no obedece ley alguna sobre cómo se han fijado las cosas y el orden en el mundo. Es así que, las circunstancias de la era actual han establecido de alguna manera, redes y nudos económicos capitalizadores de bienes comunes y de una escalada que difícilmente reconozca un final para este modelo.

Es sobre esa moldura expansiva de razones prácticas que la economía regional de Puno se desenvuelve día a día, quizás de la mejor forma. En donde las relaciones sociales, los modos de producción y de flujos económicos locales de un circuito histórico están suficiente y exponencialmente encadenados a tasas de crecimiento económico fijados y concentrados en el sector primario, particularmente, minero. Aquí, es donde las grandes dosis del mercado mundial y de capital extranjero presionan fuertemente con devorarlo.

En ese contexto y acarreando la idea pivote, Puno es de manera completa una de las regiones más importantes de una variada y extensa producción de metales en el Perú. En tal razón, no extraña que gran parte de sus territorios hayan sido concesionados por enormes compañías dedicadas a la explotación de minerales que, de manera insostenible y contra todo pronóstico, tienden a afectar negativamente la territorialidad, el ambiente y la salud pública de los moradores del altiplano, y es que, para seguir la expansión predatoria del capital, este requiere de todas maneras un ingente de zonas sacrificadas.

De lo anterior, el formato es el mismo. Pues, una vez destruido el radio de explotación de recursos o diseñado el plan de acumulación por destierro, este desemboca inmediatamente en un contraataque social que, debido al impacto nocivo de la industria mega-minera. Este último, puede unificar poblaciones que antes estuvieron incluso desarticuladas, reconduciéndolos a un mismo camino, que es, el de revertir o derrotar a la maquinaria extractiva.

No obstante, como si esto fuera fácil de predecir, las colosales compañías mineras anticipadamente o en el proceso, terminan desembolsando una mayor inversión social en áreas intervenidas por el capital con el propósito de apaciguar o reducir las protestas en su contra, y que después 
de haber moderado y seccionado al gobierno nacional en partes, llegan a convertirse en muchos casos, en el "Otro Estado". Uno que fundamentalmente aspira a la maximización de ganancias en la producción mediante el domino territorial absoluto, sin el intento de costear la vida social y de aquellas causas mortíferas que puedan provocar al medioambiente.

En esas definiciones, verdaderamente el capitalismo, cuando este se hace global, se presenta como un dominio expansivo de todos los anclajes y factores productivos de una economía local que, en el peor de los casos, acaba enterrándola. De igual manera, dentro de su operancia queda sujeta todo el terreno de la vida a una sola forma de expresión completa y de producción que se reduce, al capital. A un reino de relaciones económicas sin barreras territoriales y de sumisión del recurso humano al valor de uso y de cambio.

Dada la situación, en la inmensa meseta altiplánica, un descomunal poder materializado en megaproyectos mineros aflige a quienes han pernoctado desde sus inicios en esas tierras de gran trayecto fidedigno. Así, con el paso del tiempo, la región lacustre ha estado condenado a ser un foco de explotación minera, tanto formal, como de una minería informal e ilegal. Una realidad predestinada en gran parte a recursos minerales que se van desmoronando a la vista de miles de pobladores por la débil incisión regulatoria por parte de instituciones estatales y de los gobiernos regionales de turno en propiciar las mejoras posibles de una economía local que podría de alguna u otra manera ser sostenible y competir a nivel del globo, sin que tenga que dañar a nada y a nadie.

No obstante, frente a muchas irregularidades e inconvenientes, en lo que va de la fecha, Puno sigue siendo una de las regiones con la mayor cantidad de conflictos sociales entre latentes y activos, siendo mayoritariamente por su naturaleza y multiplicación, los CSA. Aquellos que justamente están asociados a la forma cotidiana de vivir en armonía con la naturaleza, de defenderla hasta donde se pueda, porque la tierra, resulte o no, desde estos discursos territoriales andinos no debería traducirse en renta.

Finalmente, hasta aquí, puede decirse que las estacionadas fuerzas capitalizadoras y del reformado modelo neoliberal en Puno han encontrado un debate inconcluso, de formas y contenidos que aún siguen estando en 
construcción, y más aún, en aquellas zonas denominadas como fronteras o espacios postergados en donde el capital, no encuentra, por lo pronto, límite alguno para su turbulento desempeño.

\section{Referencias Bibliográficas}

Acosta, A. (2011). Extractivismo y neoextractivismo: Dos caras de la misma maldición. En Grupo permanente de trabajo sobre alternativas al desarrollo: Más allá del desarrollo (pp. 83-121). Quito: Abya-Yala.

Andina. (2018a, 19 de abril). Ya son más de 6,000 las familias de Puno que cultivan café y cacao. Disponible en: https://andina.pe/agencia/noticia-ya-sonmas- 6000-las-familias-puno-cultivan-cafe-y-cacao- 707207.aspx

Andina. (2018b, 8 de octubre). Conozca a Walter Aduviri, el virtual gobernador regional de Puno. Disponible en: https://andina.pe/agencia/noticia-conozca-a-walter-aduviri-virtual-gobernador-regional-puno-727858.aspx

Asencios, L. V. (2016). Paradoja de la minería y pobreza en el Perú. ConCiencia EPG, 1(1), 77-84. https://doi.org/10.32654/CONCIENCIAEPG.1-1.7

Banco Central de Reserva del Perú [BCRP]. (2013). Síntesis económica de Puno. Puno. Disponible en: http://www.bcrp.gob.pe/docs/Sucursales/ Puno/2013/sintesis-puno-01-2013.pdf

Banco Central de Reserva del Perú [BCRP]. (2017). Puno: Síntesis de Actividad Económica Diciembre 2017. Puno. Disponible en: http://www.bcrp.gob.pe/ docs/Sucursales/Puno/2017/sintesis-puno-12-2017.pdf

Barraza, H. F. (2006). Conflictos socio ambientales intercampesinos por los recursos naturales. Revista de Ciencias Sociales, 2(112), 37-56. Disponible en: https://www.redalyc.org/articulo.oa?id=15311204

Berardi, A. L. (2013). Resistencia en el Valle Calchaquí. Conflictos ecológicos y distributivos en torno al proyecto megaminero Agua Rica. En Ecología política del extractivismo en América Latina : casos de resistencia y justicia socioambiental (pp. 251-268). Buenos Aires: CLACSO.

Bielschowsky, R., y Torres, M. (2018). Desarrollo e igualdad: el pensamiento de la CEPAL en su séptimo decenio. Textos seleccionados del período 2008-2018. Santiago: Naciones Unidas.

Biocca, M. (2020). Zonas de sacrificio. Neo- extractivismo y pueblos indígenas en la era post-neoliberal. Etnografías Contemporáneas, (11), 106-112. Disponible en: http://revistasacademicas.unsam.edu.ar/index.php/etnocontemp/ article/view/536 
Brand, U. (2000). ¿Entre la globalización neoliberal y el estado benefactor ? El debate sobre Global Governance. Chiapas, (10), 185-189. Disponible en: https://chiapas.iiec.unam.mx/No10/ch10brand.html

Bravo, F. (2009). Conflictos socio-ambientales y Estado en el Perú . Conflictos socio-ambientales y Estado en el Perú. En XXVII Congreso de la Asociación Latinoamericana de Sociología. VIII Jornadas de Sociología de la Universidad de Buenos Aires (pp. 1-12). Buenos Aires: Asociación Latinoamericana de Sociología.

Briceno, F. (2017, 7 de mayo). El lago Titicaca, cada vez más contaminado. El Mundo. Disponible en: https://www.lanacion.com.ar/el-mundo/el-lago-titicacacada-vez-mas-contaminado-nid1989695

Canaza-Choque, F. A. (2018a). Educación y desigualdad en el Perú: rupturas y redes de esperanza en el plan de vivir juntos. UCV HACER Rev. Inv. Cult., 7(2), 69-79. https://doi.org/10.18050/revucvhacer.v7n2a8

Canaza-Choque, F. A. (2018b). Justicia ambiental vs capitalismo global. Experiencias, debates y conflictos en el Perú. Revista de Investigaciones Altoandinas, 20(3), 369-379. https://doi.org/10.18271/ria.2018.368

Canaza-Choque, F. A. (2019). Estado y sociedad al borde del siglo XXI: tensiones y emergencias. Universidad y Sociedad, 11(5), 70-74. Disponible en: http://rus. ucf.edu.cu/index.php/rus

Canaza-Choque, F. A., y Huanca-Arohuanca, J. W. (2019). Disputas por el oro azul: gobernanza hídrica y salud pública. Revista de Salud Pública, 21(5), 1-7. https://doi.org/10.15446/rsap.v21n5.79646

Canaza-Choque, F. A., Supo, F., Ruelas, D., y Yabar, P. S. (2020). El regreso del Puma Indomable. Neoliberalismo y las luchas sociales desde la escuela pública en el sur del Perú. Revista Conrado, 16(74), 154-161. Disponible en: https://conrado.ucf.edu.cu/index.php/conrado/article/view/1345

Castro, S. (2009). Pobreza, conflictos socioambientales y minería. Análisis Económico y Social, (23), 20-23. Disponible en: http://repositorio.pucp.edu.pe/index/bitstream/handle/123456789/47429/castro_pobreza.pdf?sequence $=4$

Castro, S. (2013). Pobreza, minería y conflictos socioambientales en el Perú. Lima: INTE- PUCP.

Ccopa, H. (2014, 28 de julio). 60\% del territorio puneño es potencial de explotación minera. Los Andes. Disponible en: http://www.losandes.com.pe/oweb/ Nacional/20140728/8164 3.html 
Cely-Andrade, J. L., García-Ubaque, J. C., y Manrique-Abril, F. (2017). Calidad de vida relacionada con la salud en población minera de Boyacá. Rev. Salud Pública, 19(3), 362-367. https://doi.org/10.15446/rsap.v19n3.56163

Challenger, A., Córdova, A., Chavero, E. L., Equihua, M., y Maass, M. (2018). La opinión experta evalúa la política ambiental mexicana: Hacia la gestión de socioecosistemas. Gestión y Política Pública, 27(2), 431-473. https://doi. org/10.29265/gypp.v27i2.473

Chira, J., Ríos, C., Trelles, G., y Villareal, E. (2018). Estimación del potencial minero metálico del Perú y su contribución económica al Estado, acumulado al 2050. Lima: INGEMMET.

Comisión de Investigaciones Politai. (2013). Los límites de la articulación de los movimientos antimineros en el Perú. Revista de Ciencia Política, (6), 89109. Disponible en: http://revistas.pucp.edu.pe/index.php/politai/article/ view/14116/14732

Comisión Económica para América Latina y el Caribe [CEPAL]. (2018). Acceso a la información, la participación y la justicia en asuntos ambientales en América Latina y el Caribe: hacia el logro de la Agenda 2030 para el Desarrollo Sostenible. Santiago: Naciones Unidas.

CooperAcción. (2017). Actualidad minera del Perú $N^{o}$ 216. Lima. Disponible en: http://cooperaccion.org.pe/wp-content/uploads/2017/11/BOLETINAMP216.pdf

Cordano, A. V. (2018). El mercado del litio y la revolución de las energías renovables. Lima. Disponible en: http://repositorio.gerens.edu.pe/handle/Gerens/44

Defensoría del Pueblo [DP]. (2016). Reporte mensual de conflictos sociales $N .^{\circ} 154$ - diciembre 2016. Lima. Disponible en: https://sinia.minam.gob.pe/documentos/reporte-mensual-conflictos-sociales-ndeg-154-diciembre-2016

Defensoría del Pueblo [DP]. (2019). Reporte mensual de conflictos sociales $N .^{\circ} 179$ - enero 2019. Lima. Disponible en: https://www.defensoria.gob.pe/wp-content/uploads/2019/02/Conflictos-Sociales-Nº-179-Enero-2019.pdf

Dietz, K. (2018). Consultas populares mineras en Colombia: Condiciones de su realización y significados políticos. El caso de La Colosa. Colombia Internacional, (93), 93-117. https://doi.org/10.7440/colombiaint93.2018.04

Dirección Regional de Educación Puno [DREP]. (2015). Proyecto Educativo Regional al 2021. Puno: Gobierno Regional Puno. Disponible en: https://ugelpuno. edu.pe/web/wp-content/uploads/2017/04/PER-al-2021-Documento-paraAportes1.pdf 
Domenech, E. (2007). El banco mundial en el país de la desigualdad. Políticas y discursos neoliberales sobre diversidad cultural y educación en América Latina. En Cultura y Neoliberalismo (pp. 61-89). Buenos Aires: CLACSO.

Espinosa, Ó. (2017, 9 de septiembre). La Rinconada, el 'dorado' helado. El Pais. Disponible en: https://elpais.com/elpais/2017/09/06/planeta_futuro/1504706 117_915831.html

Falen, J. (2016, 6 de noviembre). Doce de 46 proyectos mineros enfrentan conflictos sociales. El Comercio. Disponible en: https://elcomercio.pe/peru/ doce-46-proyectos-mineros- enfrentan-conflictos-sociales-146883

Fernández, I. F. (2020). No cuestionar el trabajo es no cuestionar el capitalismo: una lectura desde la teoría crítica del valor. Utopía y Praxis Latinoamericana, 25(90), 252-263. https://doi.org/10.5281/zenodo.3872568

Fornillo, B. (2018). La energía del litio en Argentina y Bolivia: comunidad, extractivismo y posdesarrollo. Colombia Internacional, (93), 179-201. https://doi.org/10.7440/colombiaint93.2018.07

Frieden, J. A. (2007). Capitalismo Global. El trasfondo económico de la historia del siglo XX. Barcelona: Editorial Crítica.

Gledhill, J. (2017). La cara oculta de la inseguridad en México. México: Paidós.

Gordon, T., y Webber, J. (2008). Imperialism and resistance: Canadian mining companies in Latin America. Third World Quarterly, 29(1), 63-87. https:// doi.org/10.1080/01436590701726509

Goyzueta, G., y Trigos, C. (2009). Riesgos de salud pública en el centro poblado minero artesanal la Rinconada (5200 msnm) en puno, Perú. Rev Peru Med Exp Salud Publica, 26(1), 41-44. Disponible en: http://sisbib.unmsm.edu.pe/ BVRevistas/Medicina_Experimental/v26_n1/pdf/a08v26n1.pdf

Gudynas, E. (2013). La ecología política de la crisis global y los límites del capitalismo benévolo. Íconos. Revista de Ciencias Sociales, (36), 53. https://doi. org/10.17141/iconos.36.2010.391

Guerra, D. E., y Skewes, J. C. (2010). Acumulación por desposesión y respuestas locales en el remodelaje de los paisajes estuariales del sur de Chile. Chungara, Revista de Antropología Chilena, 42(2), 451-464. https://doi.org/10.4067/ S0717-73562010000200008

Harvey, D. (2005). El "nuevo" imperialismo: acumulación por desposesión. Buenos Aires: CLACSO.

Harvey, D. (2012). El enigma del capital y las crisis del capitalismo. Madrid: Akal. 
Harvey, D. (2014). Diecisiete contradicciones del capital y el fin del neoliberalismo. Ecuador: IAEN.

Homazabal, N., Maino, S., Vergara, M., y Vergara, M. (2019). Habitar en una zona de sacrificio: Análisis multiescalar de la comuna de Puchuncaví. Hábitat Sustentable, 9(2), 6-15. https://doi.org/10.22320/07190700.2019.09.02.01

Houtart, F. (2009). Deslegitimar el capitalismo. Reconstruir la esperanza. Buenos Aires: CLACSO.

Huamaní, G., Macassi, S., Galarreta, J. A., y Rojas, T. (2012). Hacia una mejor gestión de los conflictos socioambientales en el Perú. Lima: CIES.

Huwiler, L. Á., Godfrid, J., y Duárez, J. (2015). Expansión minera y protesta social en Argentina y Perú. Investigaciones Sociales, 19(35), 169-186. https://doi. org/10.15381/is.v19i35.12126

Instituto Nacional de Estadística e Informática [INEI]. (2009). Perú: estimaciones y proyecciones de población por departamento, sexo y grupos quinquenales de edad, 1995-2025. Lima. Disponible en: https://peru.unfpa.org/es/ publicaciones/publicacionesperu/INEI-Peru-Bol37-Estimaciones-Proyecciones-1995-2025.pdf

Ipenza, C., y Valencia, L. (2014). Perú. En La realidad de la minería ilegal en países amazónicos (pp. 175-218). Lima: SPDA.

López, F. (2021). Capitalism as an "institutionalized social order". Notes to the work of Nancy Fraser. Iberian Journal of the History of Economic Thought, 8(1), 93-98. https://doi.org/10.5209/ijhe.75529

Mariano, M., y Endere, M. L. (2017). Carnavales y patrimonios: diálogos sobre identidades y espacios de participación. Memorias: Revista Digital de Arqueología e Historia desde el Caribe, (32), 10-41. https://doi.org/10.14482/ memor.32.10338

Martínez, M. I. (2018). Radiografía democrática del extractivismo minero en América Latina. Geopolítica(S), 9(1), 35-62. https://doi.org/10.5209/ GEOP.54914

Matute, G., Holgado, K., y Vásquez, I. (2009). Clúster alpaquero en la región Puno. Lima: Universidad ESAN.

Mayer, S., y Vásquez, C. (2018). Retos y oportunidades del litio hallado en Puno. La Cámara, 10-12. Disponible en: https://www.camaralima.org.pe/repositorioaps/0/0/par/r7839_2/informe especial.pdf

Medina, I. (1998). Estado benefactor y reforma del Estado. Espiral, 4(11), 23-45. Disponible en: https://dialnet.unirioja.es/servlet/articulo?codigo=5664072 
Merchand, M. A. (2013). El Estado en el proceso de acumulación por desposesión favorece la transnacionalización de la minería de oro y plata en México. Paradigma Económico, 5(1), 107-141. Disponible en: https://dialnet.unirioja. es/servlet/articulo?codigo $=5954117$

Merlinsky, G. (2017). Los movimientos de justicia ambiental y la defensa de lo común en América Latina. Cinco tesis en elaboración. En Ecología política latinoamericana: pensamiento crítico, diferencia latinoamericana y rearticulación epistémica (pp. 241-264). Buenos Aires: CLACSO.

Milanovic, B. (2019). Capitalism, alone: the future of the system that rules the world. Cambridge: Harvard University.

Ministerio de Comercio Exterior y Turismo [MINCETUR]. (2018a). Reporte de comercio regional Puno - 2018. Lima. Disponible en: https://www.mincetur.gob. pe/wp-content/uploads/documentos/comercio_exterior/estadisticas_y_ publicaciones/estadisticas/reporte_regional/RRC_Puno_2018.pdf

Ministerio de Comercio Exterior y Turismo [MINCETUR]. (2018b). Reporte regional de comercio Puno. Primer semestre: 2018. Lima. Disponible en: https:// www.mincetur.gob.pe/wp-content/uploads/documentos/comercio_exterior/estadisticas_y_publicaciones/estadisticas/reporte_regional/RRC_ Puno_1Semestre_2018.pdf

Ministerio de Energía y Minas [MINEM]. (2017). Sector minería: informe multianual de inversiones - 2017. Lima. Disponible en: https://www.mef.gob.pe/ contenidos/inv_privada/app/IMI_APP_MINEM_M_2017.pdf

Ministerio de Energía y Minas [MINEM]. (2018). Empresas mineras de talla mundial con presencia en Perú y su importancia para el país y el mundo. Lima. Disponible en: http://www.minem.gob.pe/minem/archivos/file/Mineria/ PUBLICACIONES/VARIABLES/2018/BEM2018FEB.PDF

Ministerio de Energía y Minas [MINEM]. (2019). Anuario minero 2018. Lima: MINEM.

Moncada, K. (2018, 24 de septiembre). San Antonio de Putina: Minería ilegal mata la vida en Ananea. Diario Sin Fronteras. Disponible en: http://www. diariosinfronteras.pe/2018/09/24/san-antonio-de-putina-mineria-ilegalmata-la-vida-en-ananea/

Montañez, D. (2018). La teoría del sistema-mundo es negra y caribeña: capitalismo y racismo en el pensamiento crítico de Oliver Cox. Tabula Rasa, (28), 139-161. https://doi.org/10.25058/20112742.n28.7 
Murillo, D. C., y Sacher, W. (2017). Nuevas territorialidades frente a la megaminería: el caso de la Reserva Comunitaria de Junín. Letras Verdes. Revista Latinoamericana de Estudios Socioambientales, (22), 46-70. https://doi. org/10.17141/letrasverdes.22.2017.2727

Ninahuanca, C. (2018, 10 de septiembre). Se activarán 12 proyectos mineros por US\$14,746 millones en 2018. Andina. Disponible en: https://andina.pe/ agencia/noticia-se-activaran- 12-proyectos-mineros-14746-millones-2018724688.aspx

Observatorio de Conflictos Mineros en el Perú [OCM]. (2018a). $22^{\circ}$ Observatorio de conflictos mineros en el Perú. Reporte primer semestre 2018. Lima. Disponible en: http://conflictosmineros.org.pe/wp-content/uploads/2018/07/ Revista-Informe-de-Conflictos-Mineros-VII.pdf

Observatorio de Conflictos Mineros en el Perú [OCM]. (2018b). $23^{\circ}$ Observatorio de Conflictos Mineros en el Perú. Reporte segundo semestre 2018. Lima. Disponible en: http://conflictosmineros.org.pe/wp-content/uploads/2018/12/ Revista-Informe-de-Conflictos-Mineros-VIII-5-1.pdf

Ocola, J. J., y Laqui, W. F. (2017). Fuentes contaminantes en la cuenca del Lago Titicaca: Un aporte al conocimiento de las causas que amenazan la calidad del agua del maravilloso Lago Titicaca. Lima: ANA.

Pajuela, R. (2009). "No hay ley para nosotros..." Gobierno local, sociedad y conflicto en el altiplano: el caso Ilave. Lima: IEP.

Peinado, J. M. (2011). A estructura teórica centro/periferia y el análisis del sistema económico global: ¿obsoleta o necesaria? Revista de Economía Mundial, (29), 27-57. Disponible en: http://www.scielo.org.mx/pdf/soc/ v35n100/2007-8358-soc-35-100-45.pdf

Peláez, J. (2015). Legislación minera y derechos humanos: el derecho en la encrucijada. El Cotidiano, (194), 107-120. Disponible en: http://www.redalyc.org/ pdf/325/32542592011.pdf

Perú21. (2018, 5 de octubre). Corte Suprema anula sentencia a Walter Aduviri por el 'Aymarazo.' Disponible en: https://peru21.pe/peru/corte-supremaanula- sentencia-walter-aduviri-aymarazo-432644

Pinto, H. (2013). Conflicto minero Santa Ana (Puno). Investigaciones Sociales, 17(31), 207-219. https://doi.org/10.15381/is.v17i31.7909

Ponce, I. M., y Jahuira, F. A. (2019). Tutela efectiva de remediación ambiental en el sistema normativo general del ambiente como fuente de mineras de explotación ilegal. Revista Didáctica de las Ciencias Naturales, 1(1), 33-46. 
Disponible en: http://revistas.unap.edu.pe/journal/index.php/RCCNN/ article/view/251/258

Ramírez, D. E. (2015). Mining and social inclusion in Peru reality or utopia (20112013). Investigaciones Sociales, 19(34), 199-215. https://doi.org/10.15381/ is.v19i34.11761

Red Muqui. (2015). Los pasivos ambientales mineros: diagnóstico y propuestas. Lima. Disponible en: http://www.muqui.org/images/PUBLICACIONES/pasivosambientales2015.pdf

Robayo, M. L. S. (2021). Varieties of capitalism: an alternative theory to the hegemonic idea of globalization. Revista Mexicana de Ciencias Políticas y Sociales, (241), 19-43. https://doi.org/10.22201/fcpys.2448492xe.2020.241.69975

Romero, A. A., Medina, R., Puente, L., Flores, S. L., Guadalupe, E., Estanislao de, L. C., y Ramírez, V. (2008). Los residuos sólidos mineros del proceso de flotación de minerales en la cuenca del rÍo Santa - Áncash. Revista del Instituto de Investigaciones FIGMMG, 11(21), 14-18.

Saade, M. (2013). Desarrollo minero y conflictos socioambientales. Los casos de Colombia, México y el Perú. Santiago de Chile: Naciones Unidas.

Sacher, W. (2015). Megaminería y desposesión en el Sur: un análisis comparativo. Íconos. Revista de Ciencias Sociales, (51), 99-116. https://doi.org/10.17141/ iconos.51.2015.1475

Sassen, S. (2015). Expulsiones. Brutalidad y complejidad en la economía global. Buenos Aires: Katz Editores.

Solís, U. (2018). Ulises Solís, Gerente General de Macusani Yellowcake: “Depósitos de litio de Macusani garantizan 40 años de explotación." Revista Rumbo Minero, (115), 18-31. Disponible en: http://www.rumbominero.com/edicion-115/

Sparke, M. (2008). Political geography-political geographies of globalization III: resistance. Progress in Human Geography, 32(3), 423-440. https://doi. org/10.1177/0309132507086878

Stein, A. (2018). Cambio climático y conflictividad socioambiental en América Latina y el Caribe. América Latina Hoy, (79), 9-39. https://doi.org/10.14201/ alh201879939

Tamayo, J., Salvador, J., Vásquez, A., y Zurita, V. (2017). La industria de la minería en el Perú: 20 años de contribución al crecimiento y desarrollo económico del país. Lima: Osinergmin. 
Torres, C. A. (2001). Grandezas y miserias de la educación latinoamericana del siglo veinte. In Paulo Freire y la agenda de la educación latinoamericana en el siglo XXI. Buenos Aires: CLACSO.

Tudela-Mamani, J. W. (2017). Estimación de beneficios económicos por el mejoramiento del sistema de tratamiento de aguas residuales en la ciudad de Puno (Perú). Desarrollo y Sociedad, 189-237. https://doi.org/10.13043/DYS.79.6

Tumi, J. E., y Escobar-Mamani, F. (2018). Incidencia de factores sociales y políticos en la inversión ambiental del Gobierno Regional de Puno - Perú. Rev. Investig. Altoandin, 20(2), 235-250. https://doi.org/10.18271/ria.2018.367

Ulloa, A. (2016). Territory feminism in Latin America: defense of life against extractivism. Nómadas, (45), 123-139. https://doi.org/10.30578/nomadas. n45a8

Valencia-Hernández, J.-G., Muñoz-Villarreal, E.-M., y Hainsfurth, J.-C. (2017). $\mathrm{El}$ extractivismo minero a gran escala. Una amenaza neocolonial frente a la pervivencia del pueblo Embera. Luna Azul, (45), 419-445. https://doi. org/10.17151/luaz.2017.45.21

Valencia, A. (2013). Justicia ambiental y subalternidad en el Perú: construyendo oportunidades para repensar nuestra historia. Justicia y Democracia. Revista de la Academia de la Magistratura, (11), 203-232. Disponible en: http:// repositorio.amag.edu.pe/bitstream/handle/123456789/190/justicia-ambiental-subalternalidad-peru.pdf?sequence $=1$ \&isAllowed $=\mathrm{y}$

Vallejo, I., Zamora, G., y Sacher, W. (2019). Dispossession, social segregation of space and territories in resistance in Latin America. Íconos, (64), 11-32. https://doi.org/10.17141/iconos.64.2019.3695

Velásquez, J. E., Solís, L., Vigo, W. E., Rosas, Á. M., Giusti, P., Fernandez, P. A., y Cabrera, H. (2014). Evaluación de las prácticas de cuidado materno infantil en áreas con pobreza extrema del Perú, 2012. Rev Peru Med Exp Salud Publica, 31(2), 243-253. Disponible en: http://www.scielo.org.pe/pdf/rins/v31n2/ a08v31n2.pdf

Velázquez, R., Somuano, M. F., y Ortega, R. Y. (2018). David contra Goliat: ¿Cómo los movimientos ambientalistas se enfrentan a las grandes corporaciones? América Latina Hoy, (79), 41-58. https://doi.org/10.14201/alh2018794158

Wagner, L. S., y Pinto, L. H. (2013). Ambientalismo(s) y bienes naturales: desafíos al extractivismo en Argentina y Brasil. Letras Verdes. Revista Latinoamericana de Estudios Socioambientales, (14), 69-94. https://doi.org/10.17141/ letrasverdes.14.2013.994

Wallerstein, I. (1999). El moderno sistema mundial. México: Siglo XXI. 


\section{Notas al final}

1 Dentro de las tipologías, esta investigación se describe como un artículo de debate. Pues, una idea clave del presente estudio es involucrar de forma inmediata al gobierno y de sus formas descentralizadas, instituciones científicas y sociedad civil en general para canalizar en dimensión completa, real y figurativa el precepto en sí, de una expresión máxima de tendencia global denominada: capitalismo. Fuerza expansiva de trayecto-mundo apropiador de imaginarios y bienes comunes por un fuerte andamiaje de empresas y Estados poderosos que en el proceso estructural de acumulación y despojo terrenal afectan a quienes la materialización del paradigma actual a deliberado su existir, dejando en ellos, una interminable cuestión de motivaciones sociales, espaciales, acuáticas, culturales, entre otras que los enfrentan a la muerte y de aquellos desmanes provocados por la maquinaria privada. Lo que aquí se busca, en todo caso, es reconocer las reconfiguraciones que ha adoptado el capital en uno de los oasis de planisferio más altos del planeta: Puno, captando en la minería la columna vertebral de su funcionamiento, cuyas formas nucleares de gran itinerario asoman; primero, a un impuesto por contaminación y de grandes pasivos ambientales en la región, y segundo, tales costos, desde una determinada encapsulan a quienes se desplazan bajo las sombras del capital, y de otros, que resisten a su poder.

2 Docente-Investigador Social del CONCYTEC. Maestrando en Ciencias de la Educación con mención en Educación Superior por la Universidad Nacional de San Agustín de Arequipa [UNSA] y con Diplomatura de Alta Especialización en Procesos Interculturales: Política, Derecho y Educación. Magíster Scientiae en Administración de la Educación por la Universidad Nacional del Altiplano [UNA] y maestrante en Derecho Procesal y Administración de Justicia en el Departamento de Ciencias Jurídicas y Políticas de la Universidad Católica de Santa María [UCSM]. Actualmente forma parte y es Miembro Colaborador del Instituto Peruano de Derecho y Literatura [IPDL]; y, asimismo, sus principales líneas de investigación se desprenden en el marco de la teoría de la democracia, de procesos globalizadores, así como de estudios demarcados por tópicos neoliberales, de relaciones de poder y de impactos agresivos del capitalismo global y del cambio climático en las estructuras del Estado y el orden social. E-mail: fcanazach@unsa.edu.pe. Identificador ORCID: https://orcid.org/0000-0002-1929-6054 
